\title{
Moral Signaling Through Donations of Money and Time
}

\author{
Samuel G. B. Johnson ${ }^{1,2,3}$ \\ Seo Young Park ${ }^{2}$ \\ ${ }^{1}$ University of Warwick, Department of Psychology \\ ${ }^{2}$ University of Bath, School of Management \\ ${ }^{3}$ University College London, Centre for the Study of Decision-Making Uncertainty
}

Corresponding Author: Sam Johnson

Email for Correspondence: $\quad$ sgbjohnson@gmail.com

Word Count: $\quad 11,461$ (main text)

Last Revised: $\quad 14$ August 2020 (submitted revision)

Note. This is a preprint. It has not been accepted for journal publication and is not the authoritative version of record.

\section{Acknowledgements}

We thank Richard Fairchild, Haiming Hang, Josh Knobe, Yvetta Simonyan, and Craig Smith for illuminating discussion about this work, and Andrew Brown, Philip Cooper, Pierre McDonagh, Nancy Puccinelli, and Brian Squire for their support of the undergraduate research apprenticeship scheme through which this work was completed. This work was presented in workshops at the Cognitive Economics Society, the Vice-Chancellor's Research Day at the University of Bath, and the University of Warwick; we thank the workshop attendees for their feedback. This research was supported by the University of Bath School of Management. 


\begin{abstract}
Prosocial acts typically take the form of time- or money-donations. Do third-parties differ in how they evaluate these different kinds of donations? Here, we show that consumers view time-donations as more morally praiseworthy and more diagnostic of moral character than money-donations, even when the resource investment is comparable. This moral preference occurs because consumers perceive time-donations as signaling greater emotional investment in the cause and therefore better moral character; this occurs despite consumers' (correct) belief that time-donations are typically less effective than money-donations (Study 1). This effect in turn is explained by two mechanisms: People believe that time-donations are costlier even when their objective costs are equated, which happens because people rely on a lay theory associating time with the self (Study 2). The more signaling power of timedonations has downstream implications for interpersonal attractiveness in a dating context (Study 3A), employment decisions (Study 3B), and donor decision-making (Study 3). Moreover, donors who are prompted with an affiliation rather (versus dominance) goal are likelier to favor time-donations (Study 4). However, reframing money-donations in terms of time (e.g., donating a week's salary) reduced and even reversed these effects (Study 5). These results support theories of prosociality that place reputation-signaling as a key motivator of consumers' moral behavior. We discuss implications for the charity market and for social movements, such as effective altruism, that seek to maximize the social benefit of consumers' altruistic acts.
\end{abstract}

Keywords: Prosocial behavior, altruism, moral psychology, reputation signaling, charitable giving 


\section{Moral Signaling Through Donations of Money and Time}

\section{Introduction}

Meet Joan and Jane. They both work in finance; they are economically well-off; and they want to give back. Joan volunteers for 40 hours with a charity that builds houses for families in poor areas. Jane does not volunteer, but instead she donates 40 hours' of her wages to a charity that hires local carpenters to build houses. While clearly Joan and Jane both did a great thing, we can nonetheless ask: Which of them did the better thing? Does Joan or Jane reap the greater social reward for her altruism?

On the one hand, one might argue that Joan behaved more morally. Joan got her hands dirtyshe built something with her own two hands, probably met many of the people she helped, and arguably gave a piece of her self. Jane just sat in her office and did her job; she might not have given a second thought to the people she helped. Joan seems more emotionally invested.

On the other hand, there is also a good argument that Jane behaved more morally. Jane is a highly remunerated professional and she is presumably good at what she does. Relative to a carpenter, she is probably far less efficient at building houses. But relative to a carpenter, she probably earns more money in her day job: She could hire several carpenters by working her finance job and donating some of the income. Jane probably helped more people.

This paper asks: For donations of time and money that are equivalent in the resources sacrificed, which do consumers view as more morally praiseworthy? There are plausible arguments for either possibility. Although the answer is not obvious, it matters, both theoretically and practically.

A growing literature looks at factors influencing consumers' decisions to donate (e.g., Ariely, Bracha, \& Meier, 2009; Baron \& Szymanska, 2011; Berman, Barasch, Levine, \& Small, 2018; Cryder, Botti, \& Simonyan, 2017; Small, Loewenstein, \& Slovic, 2007; Zlatev \& Miller, 2016). One stream of work looks at the differences between time- and money-donations, finding that, relative to moneydonations, appeals for time-donations are more effective (Liu \& Aaker, 2008), donors view timedonations more abstractly (Macdonnell \& White, 2015), and time-donations are more strongly influenced by social expectations (Lee, Piliavin, \& Call, 1999). A separate stream of work looks at third-party evaluations of prosocial actors (e.g., Barasch, Levine, Berman, \& Small, 2014; Johnson, 2020; Klein \& Epley, 2014; Newman \& Cain, 2014). Since prosocial behavior is often motivated by the desire to maintain a good reputation (Griskevicius, Tybur, \& van den Bergh, 2010; Sperber \& Baumard, 2012), these third-party perceptions are likely to sharply influence donation decisions.

Yet, little is known about how third-parties perceive those who donate time versus money: Which type of donation is more effective for signaling moral reputation? One related study looked at donors' own attitudes toward their donations of time versus money (Reed, Aquino, \& Levy, 2007). Timedonations are tightly bound with moral self-identity: Consumers who identify strongly as a moral person tend to view time-donations as more self-expressive and therefore more moral (see also Reed et al., 2016). In other words, time-donations produce a "warmer glow" (Andreoni, 1990) to donors than do money-donations. But altruism is motivated not just by how we see ourselves, but by how others see us (Griskevicius et al., 2010; Glazer \& Konrad, 1996), and the signals we send to ourselves may differ from those we send to others. Indeed, third-parties might view inefficient but self- 
expressive donations as narcissistic rather than praiseworthy. Since people care both about their own self-image and social reputation, it is important to disentangle these two issues.

This issue also has practical implications. The effective altruism movement (MacAskill, 2015; Singer, 2015) seeks out the most efficient ways to help others. Effective altruists point out that the most effective charities may be thousands of times more effective than ineffective charities - indeed, ineffective charities can cause more harm than good. Pertinent to the current discussion, effective altruists often advocate earning-to-give-donating income from a lucrative career like banking-over more transparently altruistic careers (Singer, 1972). For example, if an investment banker donates even $10 \%$ of her income to a high-effectiveness charity, she can help many more people than if she volunteered directly. Thus, effective altruists often critique charities such as Habitat for Humanity, which brings highly compensated professionals to perform manual labor that could be more efficiently performed by carpenters. Mapping out the psychology underlying beliefs about time- versus moneydonations may help to explain the popularity of ineffective, volunteer-based charities and to design nudges that might encourage consumers to donate more effectively.

\section{Theoretical Framework}

Prior research gives good reason to predict a preference for money-donations over time-donations or to predict the converse.

Two of the main approaches to moral philosophy and psychology are outcome-based or consequentialist approaches (e.g., Bentham, 1907/1789; Mill, 1998/1861; Singer, 2011) and person-based or virtue ethics approaches (e.g., Aristotle, 1999/350 BCE; Hursthouse, 1999). According to outcome-based ethics, an act's morality is determined solely by its consequences-whether it maximizes good. According to person-based ethics, an act's morality is determined by what it reveals about the actor's characterwhether it is the act of a morally good person. Both outcome-based (Baron \& Hershey, 1988; Cushman, 2008; Greene et al., 2008) and person-based approaches (Goodwin, Piazza, \& Rozin, 2014; Uhlmann, Pizarro, \& Diermeier, 2015) command empirical support as accounts of moral judgment.

If outcome-based processes predominate, consumers should believe that the more effective donation is the more moral. Since volunteering time is usually less effective than donating the money one could have earned in that time (Singer, 1972), consumers would view money-donations as more praiseworthy than equivalent time-donations. (This assumes that consumers correctly view the moneydonation as more effective; see Studies 1 and 2.) Some findings seem to support this prediction. When evaluating the quality of decisions, consumers rely on the consequences even when they are not foreseeable (Baron \& Hershey, 1988) and demand optimality in moral decision-making (De Freitas \& Johnson, 2020; Johnson \& Rips, 2015). Most directly, when consumers are asked to compare a large donation to a relatively ineffective charity versus a small donation to a relatively effective charity, people identify the smaller but effective donation as more praiseworthy when the two options are placed side-by-side (Johnson, 2020).

However, we hypothesized that person-based processes would loom larger in this case. This is because altruistic behavior appears to have evolved in part for signaling moral reputation-our trustworthiness and cooperativeness (Goodwin et al., 2014; Griskevicius et al., 2010; Miller, 2007; Nowak \& Sigmund, 2005; Sperber \& Baumard, 2012; Uhlmann et al., 2015). On this view, humans behave altruistically (i.e., taking a personal cost to produce a social benefit) because they expect others to observe this behavior, infer their prosocial moral character, and reward them socially because they expect such social rewards to be repaid in the future. Several results support this character-based view of morality. For example, people negatively evaluate others who benefit from misfortune even if they did not contribute to the misfortune (Inbar, Pizarro, \& Cushman, 2012) and view "altruistic" acts as 
worse than doing nothing at all if the actor also benefits (Newman \& Cain, 2014). Thus, prosocial acts should be praised to the extent that they signal good character.

What drives perceptions of moral character in the context of time versus money donations? One possibility is that time-donations are seen as more diagnostic of emotional investment compared to money-donations, since people are known to use emotional investment to infer moral character. For example, when a player in an economic game self-describes as deciding based on emotion (rather than reason), that player is perceived as likelier to cooperate and as more prosocially motivated (Levine et al., 2018). Similarly, when a person does something harmful and later does something good, that person is perceived more positively if the positive act is seen as motivated by remorse (e.g., guilt or shame; Johnson \& Ahn, 2020). In the charity domain, when donors report feeling highly emotional about their cause, third-parties perceive them as more empathic and higher in moral character (Barasch et al., 2014). Although we are not aware of any direct demonstrations that time-donors are viewed as more emotionally invested, this seems intuitively plausible. Putting all this together, we hypothesize:

H1a: Time-donors (vs. money-donors) are seen as more emotionally invested in their cause. H1b: The greater perceived emotional investment of time-donors leads to greater perceived (a) moral character of the donor and (b) praiseworthiness of the donation.

We can distinguish here between two potential—albeit, we shall see, inter-related—explanations for this hypothesized effect of donation-type on emotional investment (H1a).

First, people may think of one or the other resource as more (subjectively) costly even when their objective costs are equated. According to signaling theory, the costs one is willing to take on are diagnostic of one's underlying preferences and traits because costs signal a willingness to commit resources (Gintis, Smith, \& Bowles, 2001; Grafen, 1990; Zahavi, 1975). This prediction is borne out in studies of prosocial behavior specifically, which find that when a charity's personal cost and social benefit are manipulated orthogonally, judgments of moral character (as well as praise) track cost rather than benefit in between-subjects designs (Johnson, 2020), consistent with costly signaling theory. This suggests that if people believe that time-donations are more personally costly even when their objective costs are equated, then people would think them more diagnostic of moral character. Thus:

H2: Even when objective costs are equated, people believe that time-donations are subjectively costlier than money-donations.

But why might people have such a belief? This brings us to the second potential explanation for the effect of donation-type on emotional investment. There are several converging lines of evidence that suggest that people associate time with the self more than they associate money with the self; that is, people seem to hold a "time $=$ self" lay theory. For example, people enjoy products more when time rather than money is emphasized because time-emphasis increases the salience of experiences and personal connection with the product (Mogilner \& Aaker, 2009). Similarly, activating the idea of time makes people more likely to spend time with friends and family rather than working (Mogilner, 2010)_activities more associated with the self and which tend to promote happiness - and more likely to behave ethically because time priming leads people to reflect on their self-identity (Gino \& Mogilner, 2014). People often prefer to distribute resources according to willingness to spend time rather than money-against the recommendations of economic efficiency-because people believe that time investment is a stronger signal of preferences than money investment (Shaddy \& Shah, 2018). Most directly, when evaluating their own donations, people view time-donations as more expressive of their moral self-identity than money donations (Reed et al., 2007, 2016). If time is indeed more 
associated with the self, then donations of time would indeed be more subjectively costly because one is giving away a greater part of the self. This converging set of results and theory suggests:

H3a: People have a stronger "time = self" than "money = self" lay theory.

H3b: The effect of time- versus money-donations on perceived personal cost, emotional investment, moral character, and praise will be greater for individuals higher in the "time = self' lay theory.

These hypotheses were tested in Studies 1 and 2. In addition, Studies 1 and 2 examine whether people also believe that time-donations or money-donations are more effective in producing benefits for those they are helping, as one might expect from a halo effect, or whether instead people share Singer's (1972) view that money-donations are more effective.

Study 3 examines downstream consequences of moral signaling for interpersonal relations. Moral character traits such as trustworthiness and honesty predict perceptions of in-group and out-group members better than social warmth (e.g., friendliness) or competence (e.g., intelligence) (Brambilla et al., 2012; Goodwin et al., 2014; Leach, Ellemers, \& Barreto, 2007). Indeed, people view moral traits as more central to personal identity (whether a person is "the same" over time) than even a person's memories (Strohminger \& Nichols, 2014). Together with the (hypothesized) greater moral signaling power of time-donations, these previous findings led us to hypothesize that time-donations would increase interpersonal approach, which we operationalize both in terms of personal attraction (Study 3A) and hiring decisions (Study 3B). Overall, we predict:

H4: The extent of one's time-donations predicts (a) personal attractiveness and (b) hiring decisions to a greater degree than the extent of money-donations.

Studies 4 and 5 turned to examining potential moderators and boundary conditions. A first potential moderator is the social situation. Moral behavior varies according to who will be observing that behavior and how one relates to the observers (e.g., Griskevicius et al., 2010). In many competitive situations (such as a business meeting), there is little interpersonal need to signal morality, and indeed doing so may be counterproductive. Conversely, in other situations (such as a date), it may be crucial to signal one's moral character for attracting a long-term partner. If third-parties perceive timedonations as more diagnostic of moral character than money-donations, then situations that create a need to signal moral character should provoke more time-donations. Study 4 tests:

H5: People should be more inclined to donate time (vs. money) when the social context creates a motive to signal morality.

A second potential moderator is framing. Time and money are fungible resources-we work to convert time into money and outsource labor to convert money into time. Thus, these effects might be malleable. Reframing a money-donation as a time-donation (pledging one's income during a timeperiod) should increase perceived emotional investment, and thereby judgments of moral character and praiseworthiness. Therefore, Study 5 tests:

H6: Reframing money-donations as time-donations makes donors appear more emotionally invested and higher in donor character, and donations more praiseworthy. 


\section{Study 1}

Study 1 examined whether and why people morally favor time-donations over money-donations, for similar degrees of objective personal sacrifice (H1). If time-donation signals greater emotional investment to a cause, this could lead time-donors to be seen as stronger in moral character even if their objective resource investment is equivalent to the money-donors.

Here we also began to examine the issue of perceived benefits. Singer (1972) points out that, on reflection, it is usually more efficient to hire professionals rather than to bring in non-expert volunteers (Singer, 1972). But people may not appreciate this when evaluating donors. Thus, Study 1 measured beliefs about the benefits of the donations, to test whether perceived benefit might instead drive a preference for time-donations. Thus, Study 1 aimed to equate the objective costs while making no effort to equate the benefits of the time- and money-donations, measuring participants' own conclusions in the context of an ecologically realistic pair of decision donations.

\section{Method}

We recruited 200 Americans $\left(57 \%\right.$ female, $\left.M_{\text {age }}=36.4\right)$ from Amazon Mechanical Turk. The sample size was selected a priori and achieves $90 \%$ power for effects of $d>0.23$. Participants were excluded $(N=30)$ if they incorrectly answered more than $25 \%$ of the attention check questions.

Participants read about two pairs of donors. In each pair, one had volunteered for one week in a developing country, while the other donated one week's salary to a comparable charity that hires local workers to do the same task. For example:

Megan and Kate both work in Columbus, $\mathrm{OH}$ and earn about $\$ 70,000$ per year.

Megan volunteered for one week with Build a Dream, a charity that transports people to Nepal to build houses for villagers.

Kate donated $\$ 1350$ to Care Builders, a charity that hires local carpenters to build houses for villagers in Nepal.

Since Megan and Kate's income is $\$ 70,000$, one’s week salary is $\$ 1346$. Thus, Kate's money donation is equivalent in hours of labor to Megan's time donation. Moreover, the volunteer charity always transported people to the location themselves ("...a charity that transports people to Nepal...") to sidestep the issue of transportation costs, which would increase the objective cost to the donor. See the Appendix B in the Supplementary Materials for the full text of all items.

For each vignette, participants made four judgments on scales from -5 (time-donation) to 5 (money-donation): Praiseworthiness ("Which of these two acts do you think was more morally praiseworthy?"), emotional investment ("Who do you think cares more about people in [Nepal]?"), moral reputation ("Who do you think has stronger moral character"), and benefit ("Which of these two acts do you think resulted in greater benefit to people in [Nepal]?"). The questions were on separate pages, with the vignette repeated on each page.

The order of the donation types was counterbalanced, the left/right orientation of the scale adjusted to match, and items presented in a random order; the charity and donor names were counterbalanced. For analyses, except as stated, scales were re-coded with negative numbers corresponding to the time-donation and positive numbers to the money-donation. All data are available through the Open Science Framework: https://bit.ly/2NzZqHT.

\section{Results and Discussion}

Participants viewed the time-donor as more praiseworthy than the money-donor $[M=-0.84, S D$ $=2.11 ; t(186)=-5.47, p<.001, d=-0.40$ versus 0 ], supporting $\mathrm{H} 1 \mathrm{~b}$. 
This effect was expected to be rooted in the perception that time-donors are more emotionally invested (H1a). Indeed, time-donors were seen as caring more about the people they were helping $[M$ $=-0.59, S D=1.89 ; t(186)=-4.29, p<.001, d=-0.31]$. Moreover, judgments of praise were strongly predicted by judgments of emotional investment $[b=0.76, S E=0.06, p<.001]$.

Why does perceived emotional investment have such a large effect on praiseworthiness? According to our account, emotional investment impacts perceived moral character, which itself drives judgments of praiseworthiness. Indeed, perceived emotional investment strongly predicted character judgments $[b=0.63, S E=0.05, p<.001]$, which strongly predicted praise $[b=0.84, S E=$ $0.06, p<.001]$. However, since all variables were measured at the same time it is of course difficult to definitively tease apart the causal ordering of these variables.

An alternative hypothesis is that, although we equated the sacrifice or input of the time- and moneydonations, we made no effort to equate the effectiveness or output. Although effective altruists argue that money-donations are usually more efficient (Singer, 1972), participants may not agree and may even think time-donations are more efficient (e.g., because they cut out intermediaries).

However, money-donations were in fact thought to produce greater benefits $[M=0.30, S D=$ 2.07; $t(186)=1.97, p=.051, d=0.14]$. Thus, people found time-donations more praiseworthy even though they believed they were less effective. Simultaneously entering perceived benefit, emotional investment, and character judgments into a regression, all three variables predict praise: The strongest predictor was character $[b=0.50, S E=0.08, p<.001]$, then emotional investment $[b=0.38, S E=$ $0.08, p<.001]$, then perceived benefit $[b=0.15, S E=0.05, p=.005]$. Thus, participants did place some weight on the perceived benefit of the donations, which tended to favor the money-donations. But this effect was overwhelmed by the massive effects of emotional investment and moral character.

One possible concern is that asking questions about emotional investment and perceived benefit created demand characteristics, such that participants felt experimenter demand to use these judgments in judging praise. However, Study S1 in the Supplementary Materials (Appendix A) found a similarly dramatic effect on praiseworthiness without asking about emotional investment or moral character at all. Thus, participants view time-donations as more praiseworthy than money-donations even when they are not primed to think about these other factors.

\section{Study 2}

Study 2 had three primary goals. First, it aimed to further solidify the case that time-donations are viewed as more reputation-enhancing and praiseworthy than money-donations (H1). The vignettes used in Study 1 attempt to control for costs by using the protagonist's wage rate to convert between time and money. However, these costs are controlled on a weekly rather than hourly basisintroducing the possible confound that volunteers might work different numbers of hours from a standard work week - and volunteering abroad can both increase personal sacrifice (e.g., the risks of international travel) and decrease sacrifice (e.g., the pleasure of visiting somewhere new). Moreover, the participant herself may trade off time and money differently from the protagonist in the vignette, creating a potential mismatch. Study 2 addressed these issues by examining local volunteering, matching the costs on an hourly basis, and calibrating the donations to participants' individual timemoney trade-offs. This allowed us to measure perceived costs and test the prediction that timedonations are perceived as costlier even when their objective costs are equated (H2).

A related issue is that Study 1 did not attempt to control the benefits, instead assuming that the benefits are in fact greater for money-donations (as argued by Singer, 1972) and then measuring whether participants nonetheless found the benefits greater for time-donations. Although Study 1 (and Study S1 in the Supplementary Materials) found that people do agree that benefits are (somewhat) greater 
for money-donations for an ecologically realistic situation, Study 2 equated these benefits objectively to see whether this leads people to view the time-donations as more beneficial as a halo effect.

Second, Study 2 aimed to test the role of individual differences in their general "time $=$ self" lay theory in producing the intuition that time-donors are more emotionally invested (H3). We did so by including a self-report scale that quantifies the relative diagnosticity of how time and money are used in revealing preferences. This allows us both to examine whether the "time = self" lay theory exists in general and whether its magnitude influences the magnitude of our effects.

Third, Study 2 tested a possible boundary condition-the importance of the cause. Few would disagree that fighting poverty and disease is socially important, and emotional investment in such causes seems intuitively praiseworthy. But it is unclear whether these intuitions would hold as strongly for causes that are viewed as less important. Thus, Study 2 tested this possible boundary condition by comparing donations to matched charities-one benefitting an important cause (saving endangered species) and one benefitting a less important cause (saving common animals such as rats and pigeons).

\section{Method}

We recruited 301 Americans (54\% female, $\left.M_{\text {age }}=37.8\right)$ from Amazon Mechanical Turk. Participants were excluded ( $N=71)$ if participants either (i) failed a series of attention check questions using the same criteria as Study $1(N=9)$, (ii) failed either of two attention checks embedded in the two individual difference scales $(N=44)$; or (iii) failed a manipulation check (see below; $N=18$ ). Study 2 was pre-registered at https:/ / aspredicted.org/blind.php? $\mathrm{x}=7 \mathrm{z} 37 \mathrm{xb}$.

First, participants' individual time-money trade-offs were estimated using a task similar to those used in loss aversion studies (e.g., Gächter, Johnson, \& Herrmann, 2010). Participants were asked to "Suppose you were offered the opportunity to do some freelance work that was estimated to take 50 hours. Which of the following offers is the smallest payment you would accept in exchange for this work?" with options listed in order from largest to smallest from $\$ 2500$ to $\$ 250$. The median response was $\$ 1000$ — roughly in keeping with participants' median household income $(\$ 60,000-\$ 70,000)$.

For the main task, participants read about a pair of time- and money-donations as in Study 1. Measures were taken to equate the personal sacrifice across the donations, with the volunteering taking place locally and for the same number of hours the donor would have spent at work. The vignettes were also designed to equate the benefits as much as possible, with the time-donor being a qualified professional (to avoid the criticism of volunteering that donors are often not competent) and defraying costs rather than replacing labor (to avoid the criticism of volunteering that it displaces local workers). Half of the participants were randomly assigned to read about a cause relatively high in importance:

\footnotetext{
Megan and Kate both live in Honolulu, HI and earn about $[\$ \mathrm{X}]$ per year working in the field of veterinary medicine, working 40 hours per week. Both make charitable contributions to Animal Trust, a local charity that focuses on rehabilitating endangered species of tropical birds and marine mammals that are injured.
}

Megan took one week off from work to volunteer for Animal Trust for 40 hours. Her donation of time was used to fabricate supplies that were used to save the lives of 10 endangered animals such as parrots and dolphins.

Kate donated $[\$ Y]$ to Animal Trust. Her donation of money was used to purchase supplies that were used to save the lives of 10 endangered animals such as parrots and dolphins.

For the other half of participants, the cause was relatively low in importance (“... a local charity that focuses on rehabilitating common animal species such as rodents that are injured..." and "...to save the lives of 10 common animals such as rats and pigeons"). The order of the time and money donations was random (and therefore the scale orientations were adjusted to match), as in Study 1.

The salary $\$ \mathrm{X}$ and donation amount $\$ \mathrm{Y}$ were calculated using each participant's individualized trade-off. The donation $\$ Y$ was calculated as $20 \%$ less than the amount specified in the time-money 
trade-off task, since the number of hours donated (40) was $20 \%$ lower than the number of hours used in the trade-off task (50). This was done to diminish demand characteristics while equating the time and money value to the participant. The salary $\$ \mathrm{X}$ was calculated as 50 times greater than the donation, to equate the value of the time and money value to the protagonist since the hours donated was one work-week and there are approximately 50 work-weeks in a year. Thus, the time and money donation are objectively equivalent to both the participant and the protagonist.

The main dependent measures were praiseworthiness ("Which of these two acts do you think was more praiseworthy"?) from -5 ("Megan's volunteering") to 5 ("Kate's donation"); emotional investment (a composite of three items, e.g. "Who do you think feels a stronger personal connection with animals?"; $\alpha=.88$ ) from -5 ("Megan") to 5 ("Kate") (a fourth emotional investment item was inadvertently omitted from some conditions, so we exclude this item from the measure to facilitate comparability); moral character (a composite of eight items, "Based on the situation above, who do you think is better characterized by each of the following traits?" including "trustworthy," "fair," "kind," "prudent," "dishonest" (R), "unjust" (R), "mean" (R), and "irresponsible” (R) from -5 ("Megan") to 5 ("Kate"), based on character traits studied by Dahlsgaard, Peterson, \& Seligman, 2005 and used by Johnson \& Ahn, 2020 to measure character; $\alpha=.77$ ); and benefit ("Which of these two acts do you think resulted in greater benefit to animals") and cost ("Which of these two acts do you think required a greater sacrifice?") from -5 (“Megan's donation") to 5 (“Kate's volunteering”). Each set of questions (praiseworthiness, emotional investment, moral character, and benefit/cost) were presented on their own page with the vignette text repeated at the top of the page.

In addition to attention check questions similar to those used in Study 1, participants also completed a manipulation check for the importance manipulation, indicating "In your opinion, which is the more important cause?" and selecting from "Helping endangered species such as parrots and dolphins" or "Helping common animal species such as pigeons and rats." Any participant who selected the latter option was excluded from analysis $(N=18)$.

After the main task and check questions, participants completed two individual difference scales in a random order. The key measure was a novel scale, quantifying individual differences in the strength of the "time $=$ self" versus "money $=$ self" lay theories. This scale was composed of two sets of opposite statements, such as "Our time is a deeper reflection of the self than our money" vs. "Our money is a deeper reflection of the self than our time" (R); complete items are listed in Appendix B. Scale reliability was acceptable $(\alpha=.66)$.

As an exploratory measure, participants also completed the Oxford Utilitarianism Scale (Kahane et al., 2018), which measures individual tendencies toward impartial beneficence (treating all people as of equal moral worth; e.g., "From a moral perspective, people should care about the well-being of all human beings on the planet equally; they should not favor the well-being of people who are especially close to them either physically or emotionally"; $(\alpha=.73)$ and toward instrumental sacrifice (being willing to sacrifice others for the greater good; e.g., "It is permissible to torture an innocent person if this would be necessary to provide information to prevent a bomb going off that would kill hundreds of people"; $(\alpha=.77)$. As is typical in other research (e.g., Johnson \& Ahn, 2020; Kahane et al., 2018), these two components of utilitarianism were only weakly correlated $(r=.25)$.

\section{Results}

Overall, the results mirror those of Study 1. Despite carefully equating the objective costs and benefits of the time and money donations, participants continued to believe that the time-donations were more praiseworthy and more diagnostic of emotional investment and moral character. Participants' subjective beliefs about costs and benefits also favored the time-donations (unlike Study 
1, where participants believed the money donations were more beneficial), suggesting a halo effect. All of these effects were associated with higher belief in the "time = self" lay theory, but only weakly with utilitarianism. The effects did not differ between the high- and low-importance conditions.

Praise judgments significantly favored the time-donors $[M=-1.42, S D=1.97 ; t(229)=-10.96, p$ $<.001$ vs. $0, d=-0.72$ ], and this effect was similar for the high-importance and low-importance donations $[t(228)=0.02, p=.99, d<0.01]$. Corresponding to this, the time-donors were also seen as more emotionally invested $[M=-1.63, S D=1.58 ; t(229)=-15.60, p<.001, d=-1.03]$ and as superior in moral character $[M=-0.42, S D=0.67 ; t(229)=-9.58, p<.001, d=-0.63]$, with these effects also not differing between the high-importance and low-importance conditions [ts $<1$, $p \mathrm{~s}>.40, d \mathrm{~s}<0.11$ ].

In addition, despite taking extensive measures to equate the objective costs and benefits, participants' subjective judgments reflected a belief that the time-donation required greater personal cost $[M=-$ $2.52, S D=1.99 ; t(229)=-19.26, p<.001, d=1.27]$ and resulted in greater benefit $[M=-0.98, S D=$ $1.89 ; t(229)=-7.84, p<.001, d=-0.52]$, with these effects not differing across the high- and lowimportance conditions [ts $<0.30$, ps $>.76, d s<0.04]$.

Table 1 presents the correlations among the main dependent measures and individual difference moderators ("time $=$ self" lay theory and utilitarianism). All dependent measures (praise, emotional investment, moral character, costs, and benefits) were significantly correlated with one another, often with substantial effect sizes. However, these effects were moderated by belief in the "time = self" theory. People who endorsed this theory more strongly were more prone to favor the time-donors on each of the other measures [ps $<.01]$. Of note, the mean score on this scale was significantly positive $[M=2.04, S D=1.24 ; t(229)=24.97, p<.001, d=1.65$ vs. the midpoint of 0$]$, indicating that participants were more prone to the belief the "time = self" than that "money = self," since the scale was composed of matched, opposing pairs of statements. In addition, more utilitarian participants were somewhat more disposed to favor time-donors, with this effect reaching significance for emotional investment but at most marginally for the other dependent measures.

\begin{tabular}{l|cccccc}
\hline \multicolumn{2}{c}{ Praise } & $\begin{array}{c}\text { Emotional } \\
\text { Investment }\end{array}$ & $\begin{array}{c}\text { Moral } \\
\text { Character }\end{array}$ & $\begin{array}{c}\text { Subjective } \\
\text { Costs }\end{array}$ & $\begin{array}{c}\text { Subjective } \\
\text { Benefits }\end{array}$ & $\begin{array}{c}\text { "Time }= \\
\text { Self" } \\
\text { Theory }\end{array}$ \\
\hline Emotional Investment & $.35^{* * *}$ & - & & & & \\
Moral Character & $.35^{* * *}$ & $.57^{* * *}$ & - & & & \\
Subjective Costs & $.41^{* * *}$ & $.55^{* * *}$ & $.41 * * *$ & - & & \\
Subjective Benefits & $.45^{* * *}$ & $.42^{* * *}$ & $.40 * * *$ & $.33 * * *$ & - & - \\
“Time = Self” Theory & $-.20^{* *}$ & $-.34 * * *$ & $-.19 * *$ & $-.31 * * *$ & $.19 * *$ & $-12^{\circ}$ \\
Utilitarianism & $-.12^{\circ}$ & $-.23 * * *$ & -.10 & -.11 & -.09 &
\end{tabular}

Table 1. Correlations among measures in Study 2.

Note. Entries are first-order Pearson correlations among measures. Citations are square-root transformed. "Time $=$ self" is coded such that higher numbers indicate stronger belief in "time = self" and utilitarianism is coded such that higher numbers indicate higher endorsement of utilitarianism.

\section{Discussion}

Overall, the results echo the main conclusions of Study 1. As in Study 1, time-donors were deemed more praiseworthy, emotionally invested, and higher in moral character, despite using somewhat different measures of all three of these constructs. In Study 1, we attempted to roughly equate the objective personal costs of the time- and money-donations, whereas we made no effort to equate the 
benefits in order to test whether people share Singer's (1972) view that money-donations are typically more effective. In Study 2, we took much greater pains to equate both the costs and the benefits, finding that time-donations were still seen as more praiseworthy. In addition, participants reported higher subjective beliefs in both the costs and benefits of the time-donations. This supports $\mathrm{H} 1-\mathrm{H} 2$.

We measured beliefs in the "time = self" lay theory to test whether lay theories moderate the effect of time- vs. money-donations. They do. Beliefs on average were significantly above the scale midpoint, indicating that time is more associated with the self than is money. Moreover, participants higher on these beliefs showed a stronger preference for time- over money-donors. These findings support H3.

Finally, Study 2 allowed us to examine the role of utilitarianism versus deontology-two comprehensive ethical belief systems - in moderating the effects. According to utilitarianism, the goal of morality is to seek the greatest good for the greater number. In contrast, deontology focuses on norm- and rule-following, with particular emphasis on avoiding rule-violations. Throughout the history of philosophy, these belief systems have been viewed as the chief rivals for ethical theory, and this controversy has persisted in moral psychology (e.g., Greene et al., 2008). Singer's (1972) utilitarian argument for money-donations suggests that when benefits are not equated, utilitarians should be more predisposed to money-donations. When the benefits are equated, utilitarians should still be less prone to believe that time-donations are more praiseworthy than money-donations, believing them to be equally praiseworthy. In fact, we find no evidence for this - if anything for the opposite. This is consistent with the more recent argument that utilitarianism and deontology are less psychologically fundamental than person-centered approaches, perhaps reflecting cultural constructs more than deepseated psychology (e.g., Bartels \& Pizarro, 2011; Johnson \& Ahn, 2020; Uhlmann et al., 2015).

\section{Study 3}

Moral character is central to how we interact with others (e.g., Goodwin et al., 2014). Study 3 therefore tests the extent to which time-donations versus money-donations influences perceived moral character (H1) in interpersonal contexts (dating in Study 3A and employment in Study 3B) and the extent to which these moral signals translate into interpersonal approach, as measured by interest in dating and employment (H4).

In addition to testing a downstream consequence of signaling, Study 3 also aimed to show that these signaling effects occur for real donations, reflective of the range of typical people's charitability. Thus, we recruited a sample of participants to report their actual donations of money and time, asking a separate sample of participants to then rate the first group in terms of character and attraction.

\section{Method}

Pretest. We recruited 100 Americans (72\% female, $\left.M_{\text {age }}=35.1\right)$ from Mechanical Turk. Participants were asked whether they donated money to charity in a typical year, and if so, how much money they typically donated; and whether they volunteered in a typical month, and if so, how many hours they typically volunteered. Money-donations and time-donations were elicited in a counterbalanced order. About $62 \%$ of participants donated money in a typical year, and about $44 \%$ volunteered in a typical month. Participants were also asked to describe their hobbies.

Participants. We recruited 200 Americans (62\% female, $\left.M_{\mathrm{age}}=35.6\right)$ from Mechanical Turk for Study $3 \mathrm{~A}$ and another 200 Americans $\left(50 \%\right.$ female, $\left.M_{\mathrm{age}}=38.2\right)$ for Study 3B. Participants were excluded using the same criterion as Study $1(N=10$ and 13, respectively). Study 3B was pre-registered at https://aspredicted.org/blind.php? $\mathrm{x}=\mathrm{w} 4 \mathrm{mv} 7 \mathrm{r}$. 
Study $3 \boldsymbol{A}$ materials. We used the pretest responses to construct 100 dating profiles for Study 3A, with both a male and female version of each. For example, one profile read:

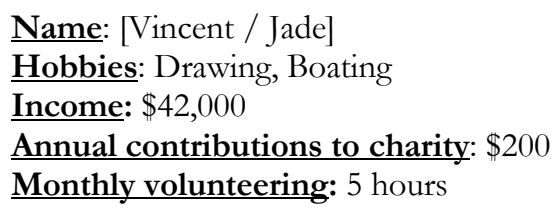

The manipulation was the charity contribution and volunteering amount, which were each yoked to the data of one pretest participant. Thus, the variability in these contributions reflects the real range of charitable activities among the participant population.

The names, hobbies, and income were assigned randomly to profiles. Names were selected from a list of most common male and female names and were randomly assigned to the 100 profiles. Each profile included 2 hobbies, one indoor-oriented and one outdoor-oriented, which were constructed from the pretest data and then randomly assigned to profiles. Income was randomly selected for each profile from between $\$ 40,000$ and $\$ 50,000$ range (around the median individual income for the United States). This was done so that the money-donations were comparable across profiles as a proportion of total income. It was important to specify income so that participants could not use charitable contributions as a signal of wealth.

Study $3 \boldsymbol{A}$ procedure. Participants were instructed that they would be viewing and evaluating profiles of potential dates, and were told that these profiles were based on real data from other Mechanical Turk workers. Participants were then asked to indicate their gender and preference for viewing profiles of men or women. Most participants (92\%) indicated opposite-gender preferences. Participants were then asked to rate several traits in importance for choosing dates on 0-10 scales. Kindness $(M=8.67)$ and sense of humor $(M=8.41)$ were rated highest, followed by morality $(M=$ 8.02), intelligence $(M=8.02)$, and shared interests $(M=7.90)$. These traits were all considered more important than physical attractiveness $(M=7.10)$, financial well-being $(M=6.40)$, or professional success $(M=5.96)$. Thus, these results confirm our impression that moral character is a key criterion when selecting potential dates.

Participants were then shown 10 profiles, randomly chosen out of the 100 profiles, with names corresponding to participants' gender preference. For each profile, participants made two attitude judgments - morality ("To what extent do you think this person is caring?") and enjoyment ("To what extent do you think this person is fun?") — and rated their dating interest ("How interested would you be in meeting this person for a date?"). These judgments were all made on 0-10 scales.

Study $3 \mathbf{B}$ materials. The materials for Study 3B were based on those from Study 3A. For example, the Study 3B version of the example above read:

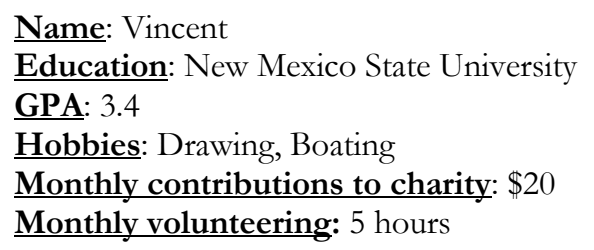

Thus, five changes were made from the versions used in Study 3A. First, either the male or female version of each profile used in Study 3A was randomly selected. Second, each applicant was assigned an educational background; 20 public universities were selected from U.S. universities ranked 100150 in the Times Higher Education ranking, and each randomly assigned to 5 of the profiles. Third, 
each applicant's GPA was randomly assigned between 3.2 and 3.5. These educational traits were selected to be relevant to employability, but restricted within a relatively narrow range so as not to swamp the variance due to other variables. Fourth, unlike Study 3A, income was not provided. Finally, applicants' monetary donations were translated from annual donations (provided in Study 3A) to monthly donations in Study 3B. The amounts used in Study 3A were divided by between 8 and 12 (with the exception of a $\$ 5 /$ year profile in Study $3 \mathrm{~A}$, changed to $\$ 1 /$ month in Study $3 \mathrm{~B}$ ), to roughly equate the amounts donated across studies while keeping the dollar amounts round.

Study $3 \boldsymbol{B}$ procedure. Participants were instructed that they would act in the role of a hiring manager, "tasked with selecting job applicants to interview and hire" and that they would be "asked to rate each candidate on a series of traits to the best of your availability given the available information." Participants then rated the importance of several traits in a potential employee on 0-10 scales, as in Study 3A. Participants rated conscientiousness highest ( $M=8.94$; "how careful, hardworking, and conscientious the employee is"), with morality following close after ( $M=8.71$; "how ethical and moral the employee is"). These traits were more important than agreeability $(M=7.54$; "how friendly and agreeable the employee is"), emotional stability ( $M=7.46$; "how relaxed and emotionally stable the employee is"), openness ( $M=7.01$; "how open and creative the employee is"), or extraversion ( $M=5.18$; "how outgoing and extraverted the employee is"). Thus, morality appears to be an especially important trait in lay theories of employability, nearly on par with conscientiousness.

Participants were then shown 10 profiles (randomly selected out of the 100). Participants completed two sets of ratings for each profile. First, they rated 12 traits. Ten of these traits were roughly based on the Big 5 short form scale (Rammstedt \& John, 2007), measuring extraversion ("outgoing", "reserved"; $r=-.76$ ), conscientiousness ("thorough", "lazy"; $r=-.64$ ), agreeableness ("friendly", "disagreeable"; $r=-.51$ ), openness ("artistic", "unimaginative"; $r=-.64$ ), and stability/neuroticism ("relaxed", "nervous"; $r=-.24$ ), with the latter trait in each pair reverse-coded. Two of the traits were measures of morality, based on Goodwin et al. (2014), which were selected to be traits that load high on morality but low on warmth to more cleanly separate these two constructs ("fair", "honest"; $r=.80$ ). These 12 traits were rated in a separate random order for each item. Finally, participants rated the employability of each applicant ("Relative to other potential candidates, how seriously do you think this candidate should be considered for the position?"). All measures were taken on scales anchored at -5 ("Far below average"), 0 ("Average"), and 5 ("Far above average").

\section{Results}

Compared to the magnitude of money-donations, the magnitude of time-donations had a larger effect on dating (Study 3A) and hiring (Study 3B) interest as well as on moral character (both studies).

Study $\mathbf{3 A}$. Analyses were conducted at the level of items $(N=100)$, averaging across participants $(M d n=10$ per version [male/female] of each item). Judgments of morality $[r(98)=.68, p<.001]$ and dating interest $[r(98)=.43, p<.001]$ were moderately to highly correlated between the male and female versions of each item, so we averaged these versions for analysis. However, results are similar when looking at the male or female profiles separately. Since money-donations and time-donations were both skewed, we transformed both variables by taking the square-root, before centering each variable at its mean and scaling by its standard deviation. Results are similar on the untransformed variables.

To test the impact on morality and attractiveness of money-donations and time-donations, we entered both variables as predictors in a multiple regression. Although both variables were predictive, time-donations $[b=0.67, S E=0.07, p<.001]$ were more predictive of perceived morality than moneydonations $[b=0.41, S E=0.07, p<.001]$. That is, whereas a $1 \mathrm{SD}$ increase in money-donations led to 
a 0.41 -point increase in perceived morality, a $1 \mathrm{SD}$ increase in time-donations led to a 0.67 -point increase. Similarly, time-donations were more predictive of perceived fun $[b=0.29, S E=0.08, p<$ $.001]$ than money-donations $[b=0.05, S E=0.08, p=.51]$, although these effects were smaller than for morality. Finally, for dating interest, the effect of time-donations $[b=0.47, S E=0.08, p<.001]$ was nearly three times the magnitude of the effect of money-donations $[b=0.17, S E=0.08, p=.040]$.

Study 3B. As for Study 3A, analyses were conducted at the level of items $(N=100)$, averaging across participants. Once again, we used multiple regression, with time-donations and moneydonations as predictors. These variables were again square-root-transformed before centering and scaling by its standard deviation, but the results are similar on the untransformed variables.

For predicting morality, time-donations $[b=0.22, S E=0.03, p<.001]$ were again more predictive than money-donations $[b=0.10, S E=0.03, p=.002]$, with more than double the effect size. Consequently, time-donations were also more predictive of hiring intentions $[b=0.33, S E=0.04, p$ $<.001]$ than were money-donations $[b=0.16, S E=0.04, p<.001]$. Indeed, as shown in Table 2 , there was no interpersonal judgment for which time-donations were not more predictive than moneydonations, except openness for which neither variable was predictive. The relatively small coefficients on stability may be due to the poor reliability of the stability measure $(r=.24)$.

\begin{tabular}{|c|c|c|}
\hline \multirow{2}{*}{ Dependent Variable } & \multicolumn{2}{|c|}{ Predictor } \\
\hline & Time Donations & Money Donations \\
\hline Extraversion & $0.33(0.06) * * *$ & $0.09(0.06)$ \\
\hline Conscientiousness & $0.26(0.04) * * *$ & $0.08(0.04) *$ \\
\hline Openness & $0.05(0.07)$ & $0.09(0.07)$ \\
\hline Agreeableness & $0.26(0.03) * * *$ & $0.09(0.03) * *$ \\
\hline Stability & $0.08(0.04) *$ & $0.05(0.04)$ \\
\hline Morality & $0.22(0.03) * * *$ & $0.10(0.03)^{* *}$ \\
\hline Employability & $0.33(0.04) * * *$ & $0.16(0.04) * * *$ \\
\hline
\end{tabular}

Table 2. Multiple regressions predicting interpersonal judgments from time- and money-donations. Note. Each row corresponds to a separate regression, with the columns giving the coefficients for the two predictors (square-root transformed and then scaled by $1 \mathrm{SD})$.

We also fit a multiple regression model fitting employability from the six interpersonal judgments. The most predictive judgment was morality $[b=0.50, S E=0.13, p<.001]$, followed by conscientiousness $[b=0.41, S E=0.11, p<.001]$, extraversion $[b=0.23, S E=0.07, p<.001]$, and openness $[b=0.16, S E=0.05, p=.005]$. Agreeableness $[b=0.07, S E=0.15, p=.63]$ and stability $[b$ $=-0.09, S E=0.12, p=.47]$ were not significant. These results are consistent both with the findings in Table 1 (large effects of time-donations on morality and conscientiousness) and participants' selfreports that conscientiousness and morality were the most important factors in hiring.

\section{Discussion}

Study 3 contributes to our investigation in two primary ways. First, it replicates the finding that time-donations have an especially large effect on perceived moral character, relative to moneydonations. Within the ordinary range of time- and money-donations (as measured among our 
participant population), a 1 SD increase in time-donations has a $63 \%$ and $120 \%$ larger impact (in terms of $b$ coefficients in Study 3A and 3B, respectively) on morality compared to a 1 SD increase in moneydonations. This goes beyond Studies 1 and 2, which pitted time- and money-donations directly against one another, by allowing us to document the independent effect of each kind of donation on perceived morality. Second, it documents a downstream consequence of perceived moral characterinterpersonal approach in both dating (Study 3A) and employment (Study 3B) contexts. This helps to support the idea that morality-signaling guides interpersonal approach $(\mathrm{H} 4)$.

Nonetheless, it remains possible that donors themselves are oblivious of these signals. Studies 13 show that these signals are received by third-parties, but they have not shown whether these signals are purposefully sent. Study 4 thus examines behavior of donors rather than third-party observers.

\section{Study 4}

If time-donations versus money-donations differ in the signals they send to third-parties, then consumers should be sensitive to social context in deciding between donation types (H5). Study 4 thus manipulated signaling motive, using a manipulation based on Maeng and Aggarwal (2018). Some participants imagined a social context in which they would had an affiliation goal and therefore a motive to signal their moral character. Other participants imagined a context in which they had a domination goal and therefore a motive to signal power and status. If donors are aware of the signals sent by their donations to third-parties, then the affiliation motive should nudge donors relatively more toward time-donations over money-donations.

\section{Method}

We recruited 499 Americans $\left(62 \%\right.$ female, $\left.M_{\text {age }}=37.6\right)$ from Mechanical Turk. Participants were excluded $(N=43)$ using criteria explained below.

First, participants' signaling motive was manipulated between-subjects. Participants first read a scenario designed to manipulate their signaling motive, based on Maeng and Aggarwal (2018, Study 3). In the dominance goal condition, participants were told to imagine they would be going on an important business trip tomorrow to finalize a negotiation. In the affiliation goal condition, participants were instead told they would be going on an important date. See Appendix B for the full text of these vignettes. To measure (first-person) signaling motives, participants were then asked "how important is it that you are perceived in the following ways tomorrow?" with separate ratings of moral character ("moral"), power ("powerful"), and status ("sophisticated") on 0-10 scales.

Next, participants' own (first-person) signaling behavior was measured. Participants were told that while preparing for tomorrow's negotiation or date, they saw a news broadcast about an earthquake in Nepal. Participant were told that they are considering making a money-donation or a time-donation to help the victims, which might potentially come up in conversation with the participant's negotiation partner or date. Participants then rated which donation they were likelier to make on a scale from -5 to 5. The order of mentioning the time- and money-donations was counterbalanced, and the scale

orientation adjusted to match. Responses were recoded so that negative numbers correspond to a time-donation preference for consistency with other studies.

Finally, participants' (third-person) signaling perceptions were measured. Participants were told about two other people who made either time-donations or money-donations. Participants rated the donors' moral character ("Who do you think is more moral?"), power ("Who do you think is more powerful?'), and status (“Who do you think is more sophisticated?”) on -5 to 5 scales. The order and scale orientation were counterbalanced to match the order of the participants' own choice. 
At the end of the study, in addition to attention check questions similar to those used in previous studies, an additional check question was asked about tomorrow's activity (e.g., business meeting, date, etc.). Participants were excluded if they either answered the latter question incorrectly or answered more than $25 \%$ of the former questions incorrectly.

\section{Results}

Overall, participants favored the time-donations more when their goal was affiliation rather than dominance. This effect was mediated by moral signaling motives and was particularly strong among participants high in the belief in the morality-signaling power of time-donations, demonstrating alignment among first-person motives, third-person judgments, and behavior.

Judgments. Looking first at participants' third-party judgments, participants once again believed that time-donations much more strongly signaled moral character than money-donations $[M=-1.34$, $S D=2.17 ; t(455)=-13.14, p<.001, d=-0.62]$. This yet again replicates the moral preference for time-donations over money-donations found in Studies 1 and 2 . However, money-donations were seen as somewhat more strongly signaling power $[M=0.41, S D=2.64 ; t(455)=3.29, p=.001, d=$ $0.15]$ and status $[M=0.50, S D=2.28 ; t(455)=4.69, p<.001, d=0.22]$. This may be due to the inference that high-power or high-status individuals would have greater scarcity of time relative to money (see Shaddy \& Shah, 2018), and therefore be likelier to choose money-donations. We note, however, that the signaling value of time vs. money donations is much smaller for power and status $(d s=0.15$ and 0.22$)$ than for morality $(d=-0.62)$.

Motives. Turning next to the first-person task, the experimental manipulation effectively shifted participants' signaling motives. Participants in the affiliation (rather than dominance) condition were higher in moral signaling motives $[M s=8.52$ vs. $6.86 ; t(454)=8.69, p<.001, d=0.81]$ but lower in power signaling $[M \mathrm{~s}=4.56$ vs. $8.92 ; t(454)=-25.23, p<.001, d=-2.36]$ and status signaling $[M \mathrm{~s}=$ 6.48 vs. $7.83 ; t(454)=-7.42, p<.001, d=-0.69]$ motives. Given that these three motives are confounded in our experimental design—and perhaps in any experimental design manipulating signaling motives through social context-we rely on regression models to tease apart these pathways.

Donation behavior. Before turning to more sophisticated modeling, we can look at the raw effects on behavior. Indeed, participants favored time-donations to a greater degree in the affiliation signaling condition $[M=0.55, S D=3.53]$ than in the dominance signaling condition $[M=1.59, S D$ $=3.42 ; t(454)=3.21, p=.001, d=0.30]$. Given the greater actual prevalence of money-donations over time-donations in real-world behavior (see Study 3), it is not surprising that participants in both conditions favored the money-donation overall; what is more impressive is that this tendency was nearly three times greater in magnitude in the dominance than in the affiliation condition.

To quantify the part of this effect due to morality signaling motive (versus power and status signaling) and to examine the interaction between first-person signaling motives and third-person signaling judgments, we fit a moderation mediation model (PROCESS Model 14; Hayes, 2013). This model used social context condition (dummy-coded; affiliation goal =1) as the independent variable $(\mathrm{X})$, first-person signaling motives as the mediator $(\mathrm{M})$, donation preference as the dependent variable (Y; coded here so that positive numbers reflect time-donation preference), and third-person morality signaling perception as the moderator (W) of the relationship between signaling motives and donation behavior. To adjust for the measured differences in status and power signaling motives across conditions, we include these motives as covariates. However, the results are nearly identical if these covariates are omitted from the model. The results are shown in Figure 1. 


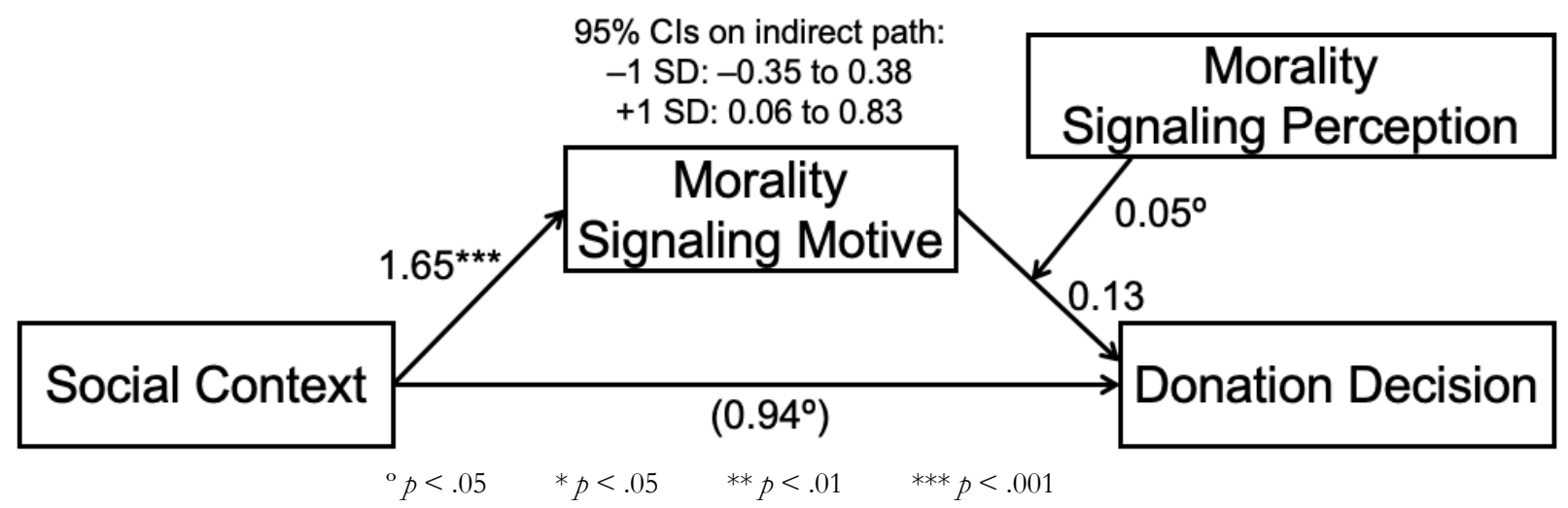

Figure 1. Moderated mediation model predicting donations from social context, motives, and perceptions. Note. Model fit using PROCESS Model 14 with status and power signaling motives as covariates.

As Figure 1 shows, there was evidence for moderated mediation over-and-above any confounding effects of status or power signaling. Social context condition (affiliation versus dominance goal) was significantly associated with the motive to signal moral character $[b=1.65, S E=0.29, p<.001]$. Firstperson moral signaling motives did not significantly predict first-person donation decisions when other variables are held constant at their means $[b=0.13, S E=0.08, p=.10]$, but crucially first-person signaling motives interacted $[b=0.05, S E=0.03, p=.070]$ with third-person signaling perceptions, which themselves had a significant effect on first-person donation decisions $[b=0.38, S E=0.07, p<$ .001]. This moderation led to a significant indirect effect of social context condition on donation decisions via morality signaling for participants who were high (+1 SD) on third-person morality signaling perception $[b=0.41,95 \%$ CI: 0.06 to 0.83$]$ but not among those who were low $[b=0.02$, 95\% CI: -0.35 to 0.38$]$.

\section{Discussion}

Study 4 showed that donation choices of time versus money are sensitive to social context (H5). With an affiliation goal, participants were likelier to favor time-donations over money-donations, particularly among participants high in the belief that time-donations send powerful signals of morality. This provides further support for the moral signaling power of time-donations, using a between-subjects design. Moreover, this shows another downstream consequence of signaling beliefs for behavior: Beliefs in third-party signaling manifest in first-person donation choices.

This study does have limitations-the social context manipulation affected not just moral character signaling motives, but also status and power signaling motives. Anticipating this problem, we measured these other motives and included them as covariates in the statistical analysis. However, it is always possible in such settings that unobserved confounds exist, reflecting other importance differences between conditions. What we can say is that (i) the manipulation did successfully manipulate moral signaling motives; (ii) that individual differences in moral signaling motives combined with individual differences in moral signaling perceptions to jointly influence behavior-a finding at odds with the idea that the results are due to unobserved confounds; and (iii) that these effects occurred over-and-above any effects of status or power signaling motives.

Study 4 also illustrates a broader point about social signaling-it depends crucially on an interaction between first-person motives and third-person social perception. Even if people are motivated to signal a trait, this will not manifest in behavior if they do not know how third-parties 
interpret the meaning of their actions. Conversely, even someone who fully understands how others judge their actions will not take signaling actions if they do not have the associated signaling goals. Thus, social context and beliefs about how social perceivers will view one's actions are both necessary to shift behaviors such as donations. Social signaling depends on shared systems of meanings between observers and doers, as reflected in the socially shared "time $=$ self" lay theory.

\section{Study 5}

If this moral preference for time-donations over money-donations is a mistake-as effective altruists such as Singer (1972) argue-then it would be useful to consider ways to reframe moneydonations to compete more effectively against time-donations in the moral marketplace. Study 5 capitalizes on the fact that time can often be converted into money and vice versa. Specifically, we tested whether reframing money-donations as time-donations would make money-donations appear more praiseworthy (H6) and, conversely, whether framing time-donations as money-donations would make time-donations appear less praiseworthy.

\section{Method}

We recruited 200 Americans $\left(57 \%\right.$ female, $\left.M_{\text {age }}=40.7\right)$ from Mechanical Turk. Participants were excluded $(N=25)$ using the same criterion as Studies 1 and 3. Study 5 was pre-registered at https://aspredicted.org/blind.php? $x=\operatorname{tr} 6 j 4 \mathrm{~g}$.

Participants read four vignettes concerning donations to different charitable causes (see Appendix B), in which one person donated time and the other person donated money. Each vignette appeared in one of four conditions in a $2 \times 2$ design, where the time-donation was framed either in terms of time or money and the money-donation was framed either in terms of money or time. In the baseline condition (time-framing/money-framing), the time-donation was framed in terms of time and the money-donation in terms of money. The baseline version of one of the vignettes read:

Megan and Kate both work in Columbus, $\mathrm{OH}$ and earn $\$ 20$ per hour. They both made contributions to a charity called Build a Dream, which helps build houses for the homeless.

Megan pledged to donate 10 hours of her time to volunteer with Build a Dream.

Kate pledged to donate $\$ 200$ of her income to Build a Dream.

A second condition (time-framing/time-framing) was identical to the baseline condition, except that the money-donation was re-described in terms of its time value:

Kate pledged to donate 10 hours' worth of her income to Build a Dream. This amounted to a cash donation of $\$ 200$.

Conversely, a third condition (money-framing/money-framing) was identical to the baseline condition, except that the time-donation was re-described in terms of its money value:

Megan pledged to donate $\$ 200$ worth of her time to Build a Dream. This amounted to volunteering for 10 hours.

Finally, a fourth condition (money-framing/time-framing) described the time-donation in terms of money and the money-donation in terms of time, using the wordings above. Participants read one vignette in each of the four conditions, assigned to condition using a Latin square. Vignettes were completed in a random order.

For each item, participants rated praiseworthiness ("Whose act do you think was more praiseworthy?"), emotional investment ("Who do you think cares more about helping the homeless"), and character ("Who do you think has stronger moral character") on scales from -5 ("Megan") to 5 ("Kate"). These judgments were all made on the same screen. 


\section{Results}

We once again see an overall preference for time-donors, but this was attenuated depending on how the donations were framed. The means are plotted in Figure 2.

In the baseline condition (i.e., time-donations framed in terms of time and money-donations framed in terms of money), participants viewed the time-donations as more praiseworthy $[M=-1.31$, $S D=1.90 ; t(174)=-9.13, p<.001, d=-0.69$ vs. 0$]$, more diagnostic of emotional investment $[M=$ $-0.85, S D=1.75 ; t(174)=-6.45, p<.001, d=0.49]$, and more revealing of good moral character $[M$ $=-0.90, S D=1.65 ; t(174)=7.23, p<.001, d=0.55]$ compared to money-donations, replicating the results of our previous studies.

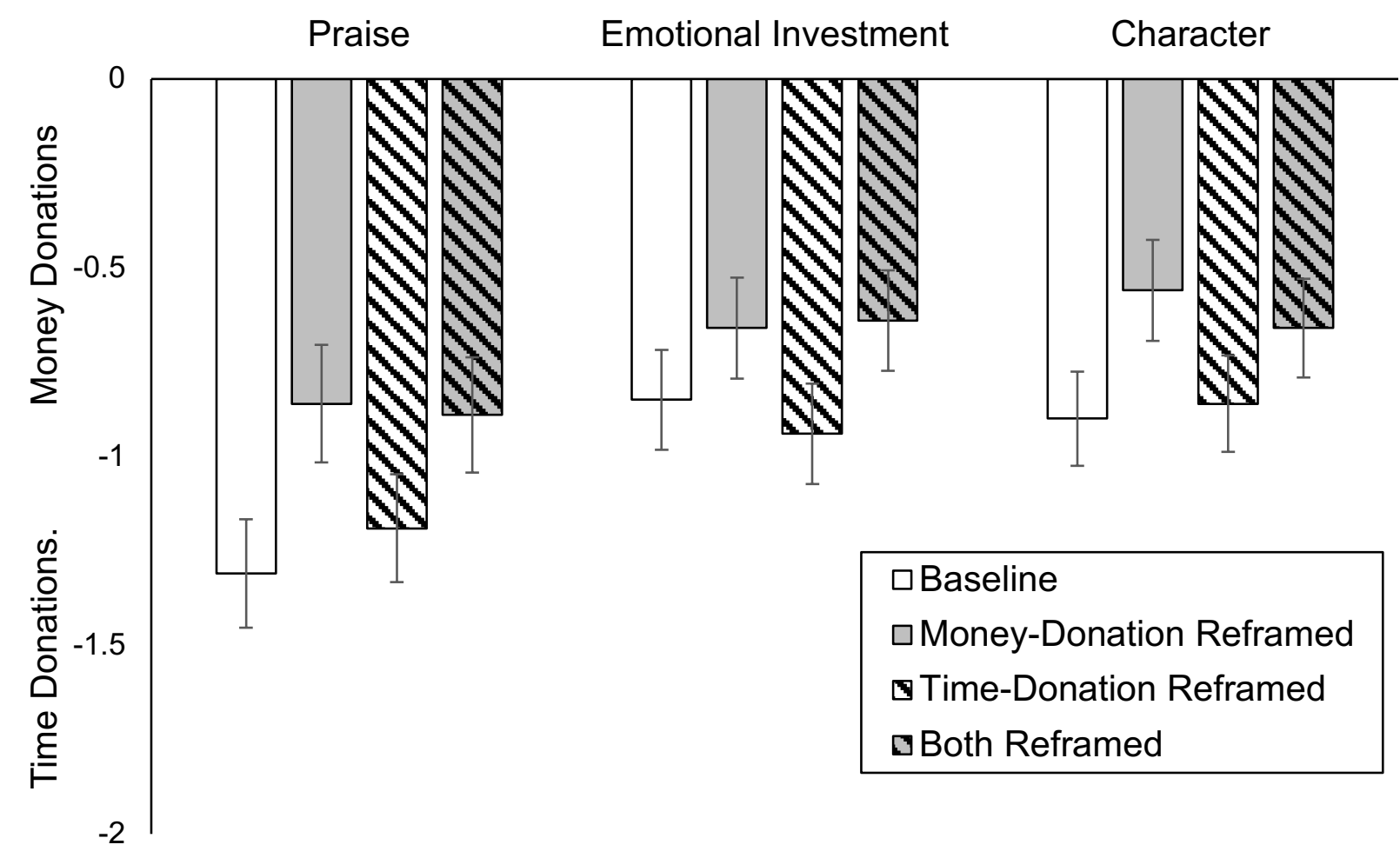

Figure 2. Results of Study 5.

Note. Possible scores on the vertical axis range from -5 (time-donation) to +5 (money-donation).

Can framing money-donations in terms of time help to make them more appealing relative to time donations? Yes: As shown in Figure 2, although participants continued to favor the time-donations, these tendencies were weaker when money-donations were framed in terms of time (time-frame/timeframe condition) compared to the baseline condition, with these effects manifesting significantly in praise $[M=-0.86, S D=2.06 ; t(174)=3.38, p<.001, d=0.23$ vs. baseline $]$ and character $[M=-0.56$, $S D=1.77 ; t(174)=2.64, p=.009, d=0.20]$, but only directionally for emotional investment $[M=-$ $0.66, S D=1.77 ; t(174)=1.43, p=.15]$. This supports H6.

We can also ask, conversely, whether framing time-donations in terms of money makes timedonations less appealing relative to money-donations. It did not: The money-frame/money-frame condition did not differ from the baseline condition on praise $[M=-1.19, S D=1.89 ; t(174)=1.12$, $p=.26, d=0.07$ vs. baseline], emotional investment $[M=-0.94, S D=1.76 ; t(174)=-0.80, p=.42$, $d=-0.05]$, or character $[M=-0.86, S D=1.69 ; t(174)=0.52, p=.61, d=-0.02]$. Since re-framing 
the time-donation in terms of money made no significant difference, it is unsurprising that when both donations are reframed (the money-frame/time-frame condition), the results look very similar to when only the money-donation is reframed (the time-frame/time-frame condition), as shown in Figure 2.

\section{Discussion}

There are two key findings here. First, reframing money-donations in terms of time is an effective way to increase the perceived praiseworthiness of the money-donations (H6), although they are still not seen as equally as praiseworthy as time-donations. Second, reframing time-donations in terms of money does not make time-donations seem less praiseworthy. One possibility is that any framing that highlights that time resources were expended is sufficient to cue the perception of emotional investment. That is, for money-donations, the time-framing is necessary because the time expenditure is otherwise not salient. But for time-donations, the time expenditure is salient whether or not the money-frame is used or not.

We also report a replication study in the Supplementary Materials (Study S2), which uses somewhat different methods to reach broadly similar conclusions about the efficacy of framing money-donations in terms of time.

\section{General Discussion}

Americans donate 8 billion hours of time to charity each year (Grimm \& Dietz, 2018), equivalent to over $\$ 200$ billion at the median American wage. For comparison, the cost of saving a human life by donating to the most effective charities is between $\$ 1,000$ and $\$ 5,000$ (GiveWell, 2019) and the cost of eradicating malaria is estimated at $\$ 90-120$ billion (Renwick, 2016). Americans' charitable impulse, if channeled effectively, could save millions of lives and transform the poorest regions of the world. Why is it that our charitable efforts fare so poorly relative to these remarkable possibilities?

There are probably many reasons for the underwhelming performance of charity. People's willingness to donate to prosocial causes is famously biased by affective influences, such as the ease of imagining an individual relative to a statistic (Small et al., 2007). Consumers often deny that one charitable cause can be objectively worthier than another (Berman et al., 2018). And even among donations to the same cause, the donation's reputational impact tends to be guided by the amount of sacrifice rather than social good (Johnson, 2020), producing little social incentive for effective giving.

The current results add yet another wrinkle: Third parties consider donations of time to be more praiseworthy than donations of money. This occurs even when the amount of sacrifice is equated and even though most people believe that money-donations are more effective at helping the recipients (Study 1) when the benefits are not objectively equated. This effect was hypothesized based on reputational accounts of moral judgment, on which praise and blame are assigned to reflect a person's perceived moral character (Goodwin et al., 2014; Uhlmann et al., 2015). We predicted-and found-that timedonations signal greater emotional investment, which in turn signals moral character (Levine et al., 2018) (Study 1). We considered two complementary mechanisms for this effect, finding evidence for both-people believe that time-donations are more costly, even when their objective costs are equated, and this bias is linked to a "time = self" lay theory (Study 2).

These moral signals manifested in third-person dating interest (Study 3) and first-person donation choices (Study 4). As further evidence that these donations act as powerful signals, between-subjects manipulations of interpersonal goal (affiliation versus dominance) led to large shifts in donation behavior, with time-donations cued more by social contexts that encourage moral signaling (Study 4). Fortunately, however, since money-donations are at root donations of time (i.e., the time worked to 
earn the amount donated), reframing money-donations in terms of time moderates this preference for time-donations (Study 5).

\section{Theoretical Implications and Future Research}

These results contribute to broader debates about moral psychology. Altruistic actions elude traditional evolutionary accounts when we help strangers we are not related to (Hamilton, 1964) nor expect to interact with again (Trivers, 1971). Reputational accounts (Miller, 2007; Nowak \& Sigmund, 2005) fill this Darwinian gap by pointing out that prosocial acts can be selfishly beneficial if they send a strong signal of cooperativeness or trustworthiness to others, incentivizing third-parties to enter into mutually beneficial relationships. The current results support this idea.

Reputational accounts are theoretically distinct from "warm glow" theories of prosociality, which emphasize that altruism is often motivated by a desire to feel good about oneself or signal positive traits to oneself - an emotionally positive but not materially beneficial goal. Indeed, such motives do partly drive preferences for time- over money-donations: Donors consider their own time-donations to be more expressive of self-identity than their money-donations (Reed et al., 2007). Our results show, however, that this "warm glow" is not the only output of time-donations-they also broadly signal one's moral reputation to third-parties. Rather than undermining the idea that "warm glow" self-signaling impacts time-donation choices, our results suggest that this motive coexists with a thirdparty signaling motive.

Going forward, these results speak to the promise of person-centered approaches to moral judgment (Goodwin et al., 2014; Uhlmann et al., 2015), which emphasize that praise and blame are often assigned not based principally on the consequences of acts, but about what those acts say about a person' character. Such approaches, though old in philosophy (Aristotle, 1999/350 BCE) are relatively new to moral psychology. Given the centrality of reputation to branding, advertising, and other key issues in marketing (e.g., Dawar \& Parker, 1994), we believe that person-centered moral psychology has broad relevance to consumer behavior. For example, this approach may be useful for understanding how firms can best manage public relations crises, how firms can maximize the moral cachet of their products for consumers to flaunt to others, and how firms can morally position themselves.

\section{Future Directions and Practical Implications}

Our theoretical framework suggests several lines of future inquiry to further understand charitable giving. First, given that cost-based thinking is at the root of the preference for time-donations, one might expect that the relative scarcity of time versus money would influence both first-person donation choices (see Shah, Shafir, \& Mullainathan, 2015) as well as third-person inferences about emotional investment and moral reputation. Second, the source of a resource may impact the moral reputation of its donor. For example, a person who received a windfall such as an inheritance might benefit little from donating it because that resource is perceived as relatively decoupled from the self due to the low time-investment required to obtain it. In contrast, if a person earns the same amount of money and then donates it, this may be perceived as a greater sacrifice because the donor's timenot just their money-is at the root of the donation.

To the extent that social signaling is in play in donor behavior (as suggested by Study 4 as well as a large literature in economics, e.g. Glazer \& Konrad, 1996; Harbaugh, 1998), this suggests that a further dimension of social context would also impact donor behavior-whether the donation is made in public or in private. For example, Griskevicius et al. (2010) find that consumers are likelier to purchase green products in public rather than private settings. On the other hand, it is possible that 
social norms become internalized over time. Indeed, this is one possible explanation for why warmglowing giving exists-we "feel good" as a proximal mechanism for "looking good." In a different domain, Rand et al. (2014) find evidence for a similar mechanism in the context of cooperative dilemmas. Because cooperation usually pays (since most real-world social encounters are repeated over time and reputation matters), most people are intuitive cooperators. Thus, deliberation — which pushes behavior more toward the optimum for a given situation-leads people to be more selfish in social situations that are not to be repeated. This suggests that the differences between public and private contexts may be relatively modest if people internalize the norm that time-donations signal moral character to a greater degree than money-donations.

These results also contribute directly to practical knowledge. On the one hand, they help to explain the proliferation of relatively ineffective charities that take donations in the form of time rather than money - the charity market is not optimizing for effectiveness, but for donor reputation. But on the other hand, they may provide clues for how to resolve this market failure. If money-donations are more effective, then the key to increasing the relative share of money versus time donations is to develop ways to signal the donors' emotional investment in the causes. Study 5 showed that one such technique is reframing money-donations in terms of time-for example, pledging a day's income to a charity rather than donating $\$ 100$. Impartiality in our distribution of charitable dollars may be critical for maximizing social good, but so is providing opportunities for donors to flaunt their moral character. 


\section{References}

Andreoni, J. (1990). Impure altruism and donations to public goods: A theory of warm-glow giving. Economic Journal, 100, 464-477.

Ariely, D., Bracha, A., \& Meier, S. (2009). Doing good or doing well? Image motivation and monetary incentives in behaving prosocially. American Economic Review, 99, 544-555.

Aristotle (1999/350 BCE). Nicomachean ethics (T. Irwin, Trans.). Indianapolis, IN: Hackett.

Barasch, A., Levine, E. E., Berman, J. Z., \& Small, D. A. (2014). Selfish or selfless? On the signal value of emotion in altruistic behavior. Journal of Personality and Social Psychology, 107, 393-413.

Baron, J., \& Hershey, J. C. (1988). Outcome bias in decision evaluation. Journal of Personality and Social Psychology, 54, 569-579.

Baron, J., \& Szymanska, E. (2011). Heuristics and biases in charity. In D. M. Oppenheimer \& C. Y. Olivola (Eds.), The science of giving: Experimental approaches to the study of charity (pp. 215-235). New York, NY: Psychology Press.

Bartels, D. M., \& Pizarro, D. A. (2011). The mismeasure of morals: Antisocial personality traits predict utilitarian responses to moral dilemmas. Cognition, 121, 154-161.

Bentham, J. (1907/1789). An introduction to the principles of morals and legislation. Oxford, UK: Clarendon Press.

Berman, J. Z., Barasch, A., Levine, E. A., \& Small, D. A. (2018). Impediments to effective altruism: The role of subjective preferences in charitable giving. Psychological Science, 29, 834-844.

Brambilla, M., Sacchi, S., Rusconi, P., Cherubini, P., \& Yzerbyt, V. Y. (2012). You want to give a good impression? Be honest!: Moral traits dominate group impression formation. British Journal of Social Psychology, 51, 149-166.

Cryder, C., Botti, S., \& Simonyan, Y. (2017). The charity beauty premium: Satisfying donors' "want" versus "should" desires. Journal of Marketing Research, 54, 605-618.

Cushman, F. (2008). Crime and punishment: Distinguishing the roles of causal and intentional analyses in moral judgment. Cognition, 108, 353-380.

Dahlsgaard, K., Peterson, C., \& Seligman, M. E. P. (2005). Shared virtue: The convergence of valued human strengths across culture and history. Review of General Psychology, 9, 203-213.

Dawar, N., \& Parker, P. (2014). Marketing universals: Consumers' use of brand name, price, physical appearance, and retailer reputation as signals of product quality. Journal of Consumer Psychology, 58 , 81-95.

De Freitas, J., \& Johnson, S. G. B. (2018). Optimality bias in moral judgment. Journal of Experimental Social Psychology, 79, 149-163.

Gächter, S., Johnson, E. J., \& Herrmann, A. (2010). Individual-level loss aversion in riskless and risky choices. CeDEx Discussion Paper Series (No. 2010-20).

Gino, F., \& Mogilner, C. (2014). Time, money, and morality. Psychological Science, 25, 414-421.

Gintis, H., Smith, E., \& Bowles, S. (2001). Costly signaling and cooperation. Journal of Theoretical Biology, 213, 103-119.

GiveWell (2019). GiveWell's cost-effectiveness analyses. GiveWell.org

Glazer, A., \& Konrad, K. A. (1996). A signaling explanation for charity. American Economic Review, 86, 1019-1028.

Gneezy, U., Keenan, E. A., \& Gneezy, A. (2014). Avoiding overhead aversion in charity. Science, 346, 632-635.

Goodwin, G. P., Piazza, J., \& Rozin, P. (2014). Moral character predominates in person perception and evaluation. Journal of Personality and Social Psychology, 106, 148-168.

Grafen, A. (1990). Biological signals as handicaps. Journal of Theoretical Biology, 144, 517-546. 
Greene, J. D., Morelli, S. A., Lowenberg, K., Nystrom, L. E., \& Cohen, J. D. (2008). Cognitive load selectively interferes with utilitarian moral judgment. Cognition, 107, 1144-1154.

Grimm, R. T., \& Dietz, N. (2018). Where are America's volunteers? A look at America's widespread decline in volunteering in cities and states. Do Good Institute Report.

Griskevicius, V., Tybur, J. M., \& van den Bergh, B. (2010). Going green to be seen: Status, reputation, and conspicuous conservation. Journal of Personality and Social Psychology, 98, 392-404.

Hamilton, W. D. (1964). The genetic evolution of social behavior. I. Journal of Theoretical Biology, 7, 116.

Harbaugh, W. T. (1998). The prestige motive for making charitable transfers. American Economic Review, $88,277-282$.

Hayes, A. F. (2013). Introduction to mediation, moderation, and conditional process analysis: A regression-based approach. New York, NY: Guilford.

Hursthouse, R. (1999). On virtue ethics. Oxford, UK: Oxford University Press.

Inbar, Y., Pizarro, D. A., \& Cushman, F. (2012). Benefiting from misfortune: When harmless actions are judged to be morally blameworthy. Personality and Social Psychology Bulletin, 38, 52-62.

Johnson, S. G. B. (2020). Dimensions of altruism: Do evaluations of charitable behavior track prosocial benefit or personal sacrifice? Available at PsyArXiv.

Johnson, S. G. B., \& Ahn, J. (2020). Principles of moral accounting: How our intuitive moral sense balances rights and wrongs. Available at PsyArXiv: https://psyarxiv.com/xetwg/.

Johnson, S. G. B., \& Rips, L.J. (2015). Do the right thing: The assumption of optimality in lay decision theory and causal judgment. Cognitive Psychology, 77, 42-76.

Kahane, G., Everett, J. A. C., Earp, B. D., Caviola, L., Faber, N. S., Crockett, M. J., \& Savulescu, J. (2018). Beyond sacrificial harm: A two-dimensional model of utilitarian psychology. Psychological Review, 125, 131-164.

Klein, N., \& Epley, N. (2014). The topography of generosity: Asymmetric evaluations of prosocial actions. Journal of Experimental Psychology: General, 143, 2366-2379.

Leach, C. W., Ellemers, N., \& Barreto, M. (2007). Group virtue: The importance of morality (vs. competence and sociability) in the positive evaluation of in-groups. Journal of Personality and Social Psychology, 93, 234-249.

Lee, L., Piliavin, J. A., \& Call, V. R. A. (1999). Giving time, money, and blood: Similarities and differences. Social Psychology Quarterly, 62, 276-290.

Levine, E. E., Barasch, A., Rand, D., Berman, J. Z., \& Small, D. A. (2018). Signaling emotion and reason in cooperation. Journal of Experimental Psychology: General, 147, 702-719.

Liu, W., \& Aaker, J. (2008). The happiness of giving: The time-ask effect. Journal of Consumer Research, $35,543-557$.

MacAskill, W. (2015). Doing good better: How effective altruism can belp you make a difference. New York, NY: Penguin.

Macdonnell, R., \& White, K. (2015). How construals of money versus time impact consumer charitable giving. Journal of Consumer Research, 42, 551-563.

Maeng, A., \& Aggarwal, P. (2018). Facing dominance: Anthropomorphism and the effect of product face ratio on consumer preference. Journal of Consumer Research, 44, 1104-1122.

Mill, J. S. (1998/1861). Utilitarianism. Oxford, UK: Oxford University Press.

Miller, G. F. (2007). Sexual selection for moral virtues. Quarterly Review of Biology, 82, 97-125.

Mogilner, C., \& Aaker, J. (2009). “The time vs. money effect": Shifting product attitudes and decisions through personal connection. Journal of Consumer Research, 36, 277-291.

Mogilner, C. (2010). The pursuit of happiness: Time, money, and social connection. Psychological Science, $21,1348-1354$. 
Newman, G. E., \& Cain, D. M. (2014). Tainted altruism: When doing some good is evaluated as worse than doing no good at all. Psychological Science, 25, 648-655.

Niedenthal, P. M., Barsalou, L. W., Winkielman, P., Krauth-Gruber, S., \& Ric, F. (2005). Embodiment in attitudes, social perception, and emotion. Personality and Social Psychology Review, 9, 184-211.

Nowak, M. A., \& Sigmund, K. (2005). Evolution of indirect reciprocity. Nature, 437, 1291-1298.

Rammstedt, B., \& John, O. P. (2007). Measuring personality in one minute or less: A 10 item short version of the Big Five Inventory in English and German. Journal of Research in Personality, 41, $203-$ 212.

Rand, D. G., Peysakhovich, A., Kraft-Todd, G., Newman, G. E., Wurzbacher, O., Nowak, M. A., \& Greene, J. D. (2014). Social heuristics shape intuitive cooperation. Nature Communications, 5, 3677.

Reed, A., Aquino, K., \& Levy, E. (2007). Moral identity and judgments of charitable behaviors. Journal of Marketing, 71, 178-193.

Reed, A., Kay, A., Finnel, S., Aquino, K., \& Levy, E. (2016). I don't want the money, I just want your time: How moral identity overcomes the aversion to giving time to prosocial causes. Journal of Personality and Social Psychology, 110, 435-457.

Renwick, D. (2016). Can malaria be eradicated? Council on Foreign Relations News Brief.

Shaddy, F., \& Shah, A. K. (2018). Deciding who gets what, fairly. Joumal of Consumer Research, 45, 833848.

Shah, A. K., Shafir, E., \& Mullainathan, S. (2015). Scarcity frames values. Psychological Science, 26, 402412.

Singer, P. (1972). Famine, affluence, and morality. Philosophy and Public Affairs, 1, 229-243.

Singer, P. (2011). Practical ethics (3rd Ed.). Cambridge, UK: Cambridge University Press.

Singer, P. (2015), The most good you can do: How effective altruism is changing ideas about living ethically. New Haven, CT: Yale University Press.

Small, D., Loewenstein, G., \& Slovic, P. (2007). Sympathy and callousness: The impact of deliberative thought on donations to identifiable and statistical victims. Organzational Beahvior and Human Decision Processes, 102, 143-153.

Sperber, D., \& Baumard, N. (2012). Moral reputation: An evolutionary and cognitive perspective. Mind \& Language, 27, 495-518.

Strohminger, N., \& Nichols, S. (2014). The essential moral self. Cognition, 141, 159-171.

Trivers, R. (1971). The evolution of reciprocal altruism. Quarterly Review of Biology, 46, 35-57.

Uhlmann, E. L., Pizarro, D. A., \& Diermeier, D. (2015). A person-centered approach to moral judgment. Perspectives on Psychological Science, 10, 72-81.

Zahavi, A. (1975). Mate selection-A selection for a handicap. Journal of Theoretical Biology, 53, 205214.

Zlatev, J. J., \& Miller, D. T. (2016). Selfishly benevolent or benevolently selfish: When self-interest undermines versus promotes prosocial behavior. Organizational Behavior and Human Decision Processes, 137, 112-122. 


\section{Supplementary Materials}

\section{Appendix A: Supplementary Studies}

\section{Study S1}

Study S1 tested the perceived praiseworthiness of time- versus money-donations found in Study 1 (H1b), using a different method.

\section{Methods}

We recruited 200 Americans $\left(61 \%\right.$ female, $\left.M_{\mathrm{ag}}=40.2\right)$ from Mechanical Turk. Participants were excluded $(N=30)$ using the same criterion as Study 1.

Participants read about four pairs of donors, similar to those used in Study 1 (see Appendix B). Participants were then asked which of acts was "more morally praiseworthy" as a forced-choice ("Megan's volunteering" or "Kate's donation"). The order of the items and the two donations within each item were randomized; the charity and donor names were counterbalanced.

\section{Results and Discussion}

Overall, participants strongly favored the time-donor over the money-donor in each pair. The time-donor was chosen $77 \%$ of the time $[t(169)=11.03, p<.001, d=0.85$ vs. chance]. Indeed, most participants $(59 \%)$ chose the time-donor for all items, whereas few $(6 \%)$ chose the money-donor for all items. These results support the idea that people's moral evaluations strongly favor time-donations over money-donations (H1b) when sacrifice is equated.

\section{Study S2}

Study S1 tested the potential for re-framing money-donatoins in terms of time found in Study 5 (H6), using a different method.

\section{Method}

We recruited 200 Americans (39\% female, $\left.M_{\text {age }}=35.9\right)$ from Mechanical Turk. Participants were excluded $(N=36)$ using the same criterion as Studies 1 and 3.

Participants read versions of three vignettes, similar to those used in Study 1 (see Appendix B). Each item described either a time-donation ("Megan volunteered for a week with Build a Dream, a charity that transports people to Nepal to build houses for villagers"), a money-donation ("Megan donated $\$ 1350$ to Build a Dream, a charity that hires local carpenters to build houses for villagers in Nepal"), or a time-framed money-donation ("Megan pledged to donate all of her earnings for one week to Build a Dream, a charity that hires local carpenters to build houses for villagers in Nepal") that was equated for donation amount. Beneath each donation, participants judged the praiseworthiness of the donation, emotional investment of the donor, and donor's moral character on 
0-10 scales. The three items were counterbalanced with the three conditions using a Latin square and items presented in a random order.

\section{Results}

Does reframing money-donations in terms of time improve their praiseworthiness? Relative to the money frame, the time-framed money-donations were deemed more praiseworthy $[M \mathrm{~s}=7.82 \mathrm{vs.} \mathrm{7.29}$; $t(163)=4.68, p<.001, d=0.27]$ and their donors higher in emotional investment $[M \mathrm{~s}=8.02 \mathrm{vs} .7 .59$; $t(163)=3.68, p<.001, d=0.22]$ and moral character $[M \mathrm{~s}=8.01$ vs. $7.63 ; t(163)=3.73, p<.001, d=$ $0.20]$. Thus, framing money-donations in terms of time improves the moral standing of the donations and donors (H6).

Indeed, the time-framed money-donations were even seen more favorably than the timedonations themselves, significantly on praise $[M s=7.82$ vs. $7.35 ; t(163)=3.40, p<.001, d=0.22]$ and emotional investment $[M \mathrm{~s}=8.02$ vs. $7.77 ; t(163)=2.67, p=.008, d=0.13]$ though only directionally for character $[M \mathrm{~s}=8.02$ vs. $7.87 ; t(163)=1.36, p=.18, d=0.08]$. This may have occurred because people correctly perceive money-donations as more effective than time-donations (as shown in Study 1), while the time-framing avoids the countervailing perception that the donor is emotionally uninvolved.

One wrinkle here is that, unlike in all other studies reported in this article, the (unframed) time and money donations themselves did not consistently differ. The only measure to significantly differ between time and money donations was moral character $[M s=7.87$ vs. $7.63 ; t(163)=2.13, p=.035$, $d=0.13$ ], with this difference of modest magnitude compared to the other experiments. Praise judgments did not significantly differ between time and money donations $[M \mathrm{~s}=7.35$ vs. $7.29 ; t(163)$ $=0.50, p=.62, d=0.03]$, nor did emotional investment $[M \mathrm{~s}=7.77$ vs. $7.59 ; t(163)=1.40, p=.16, d$ $=0.09]$, although both effects were in the predicted direction.

\section{Discussion}

The current results lead to broadly similar conclusions to Study 5: Money-donations can be reframed in terms of time to be seen as more effective. However, this study has two limitations that Study 5 in the main text does not have. First, only the re-framed time condition was described in terms of "pledging," which could itself lead to greater perception of investment compared to the unframed time and money conditions. Indeed, the fact that the reframed money-donation was seen as even more praiseworthy than the time-donation suggests that this confound may be partly driving the results. Study 5 used much more carefully controlled wordings and reached similar conclusions. Nonetheless, we include Study S2 in the interest of completeness and to demonstrate a particularly effective way ("pledge" language) to highlight emotional investment.

A second limitation is the failure of Study 5 to clearly replicate the original time vs. money finding that we demonstrate repeatedly in the main text. We are unsure what accounts for this difference, aside from perhaps statistical noise (since the character measure does indeed reach significance and the others are directionally consistent with predictions). One possibility is that the excessively strong (and arguably confounded) manipulation of "pledging" language artificially induced smaller differences between the other conditions, since the design was within-subjects. In any event, we replicate our original findings in Study 5 at very low alpha levels (.001), demonstrating robust evidence for the time vs. money effect. 


\section{Appendix B: Methodological Details}

\section{Main Studies}

\section{Study 1}

Procedure: Within each item, the materials were counterbalanced by reversing whether the first donation in each pair was a time-donation (e.g., Megan volunteered with Build a Dream) or money-donation (e.g., Megan donated $\$ 1350$ to Build a Dream). This counterbalances whether the time- or money-donation is mentioned first, which character made the time-versus money-donation, and which organization oversaw the timeversus money-donations. Items were completed in a random order.

Instructions: In this study, you will read some two brief stories about people's behavior, and answer some questions. We are interested in your opinion, and there are no right or wrong answers. There will be a total of two stories to read. Please click on the arrow to proceed.

\section{Items and Measures}

Megan and Kate both work in Columbus, $\mathrm{OH}$ and earn about \$70,000 per year.

Megan volunteered for one week with Build a Dream, a charity that transports people to Nepal to build houses for villagers.

Kate donated $\$ 1350$ to Care Builders, a charity that hires local carpenters to build houses for villagers in Nepal.

Which of these two acts do you think was more morally praiseworthy? $\quad-5$ (Megan's volunteering) to 5 (Kate's donation)

Who do you think cares more about people in Nepal?

-5 (Megan) to 5 (Kate)

Who do you think has stronger moral character? $\quad-5$ (Megan) to 5 (Kate)

Which of these two acts do you think resulted in greater benefit to people in Nepal? -5 (Megan's volunteering) to 5 (Kate's donation)

Hugh and Jack work in Austin, TX and both earn about $\$ 80,000$ per year.

Hugh volunteered for a week with Delta Fix, a charity that transports volunteers to look after patients at a hospital in Vietnam.

Jack donated \$1540 to Viet Docs, a charity which hires local villagers to look after patients at a hospital in Vietnam.

Which of these two acts do you think was more morally praiseworthy?

Who do you think cares more about people in Vietnam?

Who do you think has stronger moral character?

Which of these two acts do you think resulted in greater benefit to people in Vietnam? -5 (Hugh's volunteering) to 5 (Jack's donation)

-5 (Hugh's volunteering) to 5 (Jack's donation) -5 (Hugh) to 5 (Jack)

-5 (Hugh) to 5 (Jack)

Attention Check. Please check all of the following that were mentioned on the previous pages: carpenter (T), hospital (T), coffee $(\mathrm{F})$, concrete $(\mathrm{F})$. [These options were presented in a random order.]

\section{Study 2}

Procedure: Participants were randomly assigned to either the high-importance or low-importance version. The order of mentioning the time and money donations was counterbalanced, with the left/right orientation of the scales adjusted to match this order. Donation amounts were calibrated based on the time/ money trade-offs made by each participant in the "calibration" section below. Dependent measures were presented on separate screens in the order listed below, with the vignette repeated at the top of each page, with the praiseworthiness question on its own page, followed by the four emotional investment questions on their own page, followed by the moral character questions (presented in a random order) on their own page, followed by the benefit and cost questions on their own page. The vignette was repeated at the top of each page.

Instructions: In this study, you will read a brief story about some behavior, followed by a few additional questions. Please pay close attention to this information because there will be some questions about it at the end of the study. Overall, this study takes about 3-5 minutes to complete. 
Calibration: Suppose you were offered the opportunity to do some freelance work that was estimated to take 50 hours. Which of the following offers is the smallest payment you would accept in exchange for this work?

(Payment of $\$ 2500 / \$ 2000 / \$ 1500 / \$ 1250 / \$ 1000 / \$ 875 / \$ 750 / \$ 625 / \$ 500 / \$ 375 / \$ 250)=\$ X$

\section{$\underline{\text { Items and Measures }}$}

High importance condition: Megan and Kate both live in Honolulu, HI and earn about $\$\{\mathrm{X} * 40\}$ per year working in the field of veterinary medicine, working 40 hours per week. Both make charitable contributions to Animal Trust, a local charity that focuses on rehabilitating endangered species of tropical birds and marine mammals that are injured.

Megan took one week off from work to volunteer for Animal Trust for 40 hours. Her donation of time was used to fabricate supplies that were used to save the lives of 10 endangered animals such as parrots and dolphins.

Kate donated $\$\{\mathrm{X} * 0.8\}$ to Animal Trust. Her donation of money was used to purchase supplies that were used to save the lives of 10 endangered animals such as parrots and dolphins.

Low importance condition: Megan and Kate both live in Honolulu, HI and earn about $\$\{\mathrm{X} * 40\}$ per year working in the field of veterinary medicine, working 40 hours per week. Both make charitable contributions to Animal Trust, a local charity that focuses on rehabilitating common animal species such as rodents that are injured.

Megan took one week off from work to volunteer for Animal Trust for 40 hours. Her donation of time was used to fabricate supplies that were used to save the lives of 10 common animals such as rats and pigeons.

Kate donated $\$\{\mathrm{X} * 0.8\}$ to Animal Trust. Her donation of money was used to purchase supplies that were used to save the lives of 10 common animals such as rats and pigeons.

Which of these two acts do you think was more praiseworthy?

-5 (Megan’s volunteering) to 5 (Kate’s donation)

Who do you think cares more about animals?

Who do you think. feels a stronger personal connection with animals?

-5 (Megan) to 5 (Kate)

Who do you think spends more time thinking about animals in their spare time?

Who do you think is more emotionally invested in other charitable causes?

-5 (Megan) to 5 (Kate)

-5 (Megan) to 5 (Kate)

-5 (Megan) to 5 (Kate)

Based on the situation above, who do you think is better characterized by each of the following traits?

(Trustworthy, Fair, Kind, Prudent, Dishonest, Unjust, Mean, Irresponsible) $\quad-5$ (Megan) to 5 (Kate)

Which of these two acts do you think resulted in greater benefit to animals?

-5 (Megan's volunteering) to 5 (Kate's donation)

Which of these two acts do you think required a greater sacrifice?

-5 (Megan's volunteering) to 5 (Kate's donation)

Attention Check. Please indicate which of the following that were mentioned on the previous pages: veterinary medicine $(\mathrm{T})$, volunteering $(\mathrm{T})$, animals $(\mathrm{T})$, Honolulu, HI $(\mathrm{T})$, coffee $(\mathrm{F})$, concrete $(\mathrm{F})$, Shanghai $(\mathrm{F})$, kitchen table $(\mathrm{F})$. [These options were presented in a random order.]

Manipulation Check. In your opinion, which is the more important cause?

(Helping endangered species such as parrots and dolphins or Helping common species such as pigeons and rats)

Time-Money Scale: To what extent do you disagree or agree with each of the following statements?

If you want to see what a person really values, look at how they spend their time.

Our time is a deeper reflection of the self than our money.

Time is our most important resource.

If you want to see what a person really values, look at how they spend their money.

Our money is a deeper reflection of the self than our time.

Money is our most precious resource.

This is an attention check. Please choose 4 .

-5 (strongly disagree) to 5 (strongly agree)

Oxford Utilitarianism Scale: As given in Kahane et al. (2018). Scales from -5 (strongly disagree) to 5 (strongly agree), plus one attention check question ("This is attention check. Please choose -3."). 


\section{Study 3A}

Procedure: Participants randomly viewed 10 out of 100 possible profiles, with the gender of the name adjusted to match the participant's stated gender preference. The following profiles are arbitrarily selected examples. Dependent measures were presented on the same page as each profile, with the three judgments in the order given below.

Instructions: In this study, you will see information about 10 potential dates. For each potential date, you will be asked to answer some questions, including your interest in meeting that person. Please note that these dating profiles are based on real answers from other Mechanical Turk workers, although their names have been changed. To help us show you the most relevant dates, please answer the following questions.

I am $a . .$. [man / woman]

I am interested in... [men / women]

Please rate the importance of each of the following traits in a potential date. $\quad 0$ (not very important) to 10 (extremely important) (Morality, Kindness, Intelligence, Physical attractiveness, Professional success, Financial well-being, Sense of humor, Similar interests)

\section{Sample Items and Measures}

Name: [Sebastian / Liliana]

Hobbies: Digital art, Tennis

Income: $\$ 41,000$

Annual contributions to charity: $\$ 50$

Monthly volunteering: 1 hour

Name: [Luke / Scarlett]

Hobbies: Photography, Swimming

Income: $\$ 47,000$

Annual contributions to charity: $\$ 0$

Monthly volunteering: 10 hours
Name: [Landon / Emily]

Hobbies: Painting, Skiing

Income: $\$ 41,000$

Annual contributions to charity: $\$ 1,000$

Monthly volunteering: 0 hours

Name: [Ryan / Isabella]

Hobbies: Violin, Running

Income: $\$ 45,000$

Annual contributions to charity: $\$ 0$

Monthly volunteering: 0 hour

To what extent do you think this person is caring? $\quad 0$ to 10

To what extent do you think this person is fun? $\quad 0$ to 10

How interested would you be in meeting this person for a date? 0 to 10

Attention Check. Please indicate which of the following pieces of information were given in the profiles: name (T), hobbies $(\mathrm{T})$, income $(\mathrm{T})$, charitable donations $(\mathrm{T})$, volunteering $(\mathrm{T})$, photograph $(\mathrm{F})$, age $(\mathrm{F})$, body type $(\mathrm{F})$, hair color $(\mathrm{F})$, favorite color $(\mathrm{F})$. [These options were presented in a random order.]

\section{Study 3B}

Procedure: Participants randomly viewed 10 out of 100 possible profiles. The following profiles are arbitrarily selected examples. Dependent measures were presented on the same page as each profile, with the 12 personality judgments in a random order, then the employment judgment.

Instructions: In this study, you will imagine that you are a hiring manager, tasked with selecting job applicants to interview and hire. On the following pages, you will see profiles of 10 applicants to a job. You will be asked to rate each candidate on a series of traits to the best of your ability given the available information and to give an overall rating to the desirability of hiring each applicant. Please note that this information is based on real answers from other Mechanical Turk workers, although their names have been changed.

Please rate the importance of each of the following traits in a potential employee. 0 (not very important) to 10 (extremely important) (How outgoing and extraverted the employee is; How careful, hard-working, and conscientious the employee is; How friendly and agreeable the employee is; How open and creative the employee is; How relaxed and emotionally stable the employee is; How ethical and moral the employee is). 


\section{Sample Items and Measures}

Name: Liliana

Education: State University of New York - Binghamton

GPA: 3.4

Hobbies: Digital art, Tennis

Monthly contributions to charity: $\$ 5$

Monthly volunteering: 1 hour

Name: Scarlett

Education: New Mexico State University

GPA: 3.4

Hobbies: Photography, Swimming

Monthly contributions to charity: $\$ 0$

Monthly volunteering: 10 hours
Name: Emily

Education: New Jersey Institute of Technology

GPA: 3.4

Hobbies: Painting, Skiing

Monthly contributions to charity: $\$ 100$

Monthly volunteering: 0 hours

Name: Isabella

Education: University of Wisconsin - Milwaukee

GPA: 3.4

Hobbies: Violin, Running

Monthly contributions to charity: $\$ 0$

Monthly volunteering: 0 hours

Measures: To what extent do you think the following are true of this candidate?

(Reserved, Outgoing, Thorough, Lasy, Friendly, Disagreeable, Artistic, Unimaginative, Nervous, Relaxed, Fair, Honest)

-5 (far below average) to 5 (far above average)

Relative to other potential candidates, how seriously do you think this candidate should be considered for the position? -5 (far below average) to 5 (far above average)

Attention Check: Please indicate which of the following pieces of information were given in the profiles: name (T), hobbies $(\mathrm{T}), G P A(\mathrm{~T})$, charitable donations $(\mathrm{T})$, volunteering $(\mathrm{T})$, photograph $(\mathrm{F})$, age $(\mathrm{F})$, IQ score $(\mathrm{F})$, current employer $(\mathrm{F})$, favorite color $(\mathrm{F})$. [These options were presented in a random order.]

\section{Study 4}

Procedure: Participants received either the dominance or affiliation goal prompt (between-subjects). The order of the two donations was counterbalanced in all prompts and scales.

Instructions: In this study, you will be asked to imagine yourself in a scenario, and to describe how you would behave in that scenario. The scenario is explained across a few pages of questions. Please read this information carefully. Please click on the arrow to proceed.

\section{$\underline{\text { Manipulation }}$}

Dominance Goal (DG): Imagine you are an executive at an appliance company, making about $\$ 200,000$ per year, and that you are going on an important business trip tomorrow. Your company has recently engaged in negotiating for a merger with a public company. It is one of the largest deals of the year, and the winner of this negotiation can expect great profits from this mega merger. Your counterpart has been in a stronger position throughout this negotiation and has counter-offered a higher price. This deal is potentially of great importance to your future career.

In tomorrow's negotiation, you hope to finalize the deal. The goal in this negotiation is to win and get the best deal that you can get. But you have some doubts about how your negotiation opponent perceives you - in particular, you aren't sure whether your opponent sees you as the tough negotiator that you are. Therefore, it is important to show your opponent how dominant you are, in order to get the best deal possible.

Affiliation Goal (AG): Imagine you are an executive at an appliance company, making about $\$ 200,000$ per year, and that you are going on a very special date tomorrow. You recently signed up for okcupid.com and met this person online. You two have been chatting and emailing each other for over two months. Recently you two have been talking on the phone, and this person seems to be just the right one for you. This date is potentially of great importance to your future romantic life. 
In tomorrow's date, you hope to take the relationship to the next level. The goal is to really bond with this person. But you have some doubts about the way your date perceives you - in particular, you aren't sure whether your date sees you as the sensitive person that you are. Therefore, it is important to show your date how kind you are, in order to take things to the next level.

Manipulation check. In your opinion, how important is it that you are perceived in the following ways tomorrow? (Moral, Powerful, Sophisticated) $\quad 0$ (Not at all important) to 10 (Extremely important)

\section{$\underline{\text { Measures }}$}

Donation Prompt. Today, while you are preparing for tomorrow's [negotiation / date], you see a news broadcast about a horrible earthquake in Nepal.

The earthquake killed over 5000 people and injured thousands more. Numerous people are in hospitals, many children have been orphaned, and some people are still trapped in the rubble.

You learn that various charities are soliciting volunteers and donations to help clear rubble and rescue survivors. There are two ways you are thinking of contributing. You could donate $\$ 4000$, which could help to bring in equipment and hire rescue workers. Or you could go to Nepal and volunteer for a week to help rescue victims directly.

You would have contributed anyway, but it does occur to you that your contribution is likely to come up in conversation [before the negotiation / during the date]. You are conscious of the fact that your contribution could affect the way that your [negotiation opponent / date] thinks about you.

You weigh your options. What are you likelier to decide?

-5 (Much likelier to donate $\$ 4000$ ) to 5 (Much likelier to volunteer for a week)

Third-Party Judgments: Suppose that two people decided to make a contribution to help the earthquake victims. Megan donated $\$ 4000$ and Kate volunteered for a week.

Who do you think is more moral? $\quad-5$ (Megan) to 5 (Kate)

Who do you think is more powerful? $\quad-5$ (Megan) to 5 (Kate)

Who do you think is more sophisticated? -5 (Megan) to 5 (Kate)

Attention Check 1: Please check all of the following that were mentioned on the previous pages: news broadcast (T), earthquake $(\mathrm{T}), \operatorname{Nepal}(\mathrm{T})$, volunteering $(\mathrm{T})$, donation $(\mathrm{T})$, flood victims $(\mathrm{F})$, fire $(\mathrm{F})$, politician $(\mathrm{F})$, sandwiches $(\mathrm{F})$, Rome $(\mathrm{F})$.

[These options were presented in a random order.]

Attention Check 2: According to the story, what are you doing tomorrow?: having a business meeting (T in DG condition), going on a date ( $\mathrm{T}$ in $\mathrm{AG}$ condition), appearing on television $(\mathrm{F})$, taking an examination $(\mathrm{F})$, going to your high school reunion $(\mathrm{F})$. [These options were presented in a random order.]

\section{Study 5}

Procedure: For each vignette, participants saw the time-donation either in the time-frame or the money-frame and the money-donation either in the time-frame or the money-frame, forming a 2x2 design. The four vignettes were counterbalanced with the four cells of the design using a Latin square. Items were completed in a random order and dependent measures were presented on the same screen.

Instructions: In this study, you will read some brief stories about people's behavior, and answer some questions. We are interested in your opinion, and there are no right or wrong answers. Please click on the arrow to continue.

\section{Items and Measures}

Megan and Kate both work in Columbus, $\mathrm{OH}$ and earn $\$ 20$ per hour. They both made contributions to a charity called Build a Dream, which helps build houses for the homeless.

[Time-framed time-donation] Megan pledged to donate 10 hours of her time to volunteer with Build a Dream. 
[Money-framed time-donation] Megan pledged to donate $\$ 200$ worth of her time to Build a Dream. This amounted to volunteering for 10 hours.

[Money-framed money-donation] Kate pledged to donate $\$ 200$ of her income to Build a Dream.

[Time-framed money-donation] Kate pledged to donate 10 hours' worth of her income to Build a Dream. This amounted to a cash donation of $\$ 200$.

Whose acts do you think was more praiseworthy?

Who do you think cares more about helping the homeless?

Who do you think has stronger moral character?

$$
\begin{aligned}
& -5 \text { (Megan) to } 5 \text { (Kate) } \\
& -5 \text { (Megan) to } 5 \text { (Kate) } \\
& -5 \text { (Megan) to } 5 \text { (Kate) }
\end{aligned}
$$

Rob and Bill both work in Tempe, AZ and earn $\$ 25$ per hour. They both made contributions to a charity called Love Farm, which helps fight hunger.

[Time-framed time-donation] Rob pledged to donate 10 hours of his time to volunteer with Love Farm.

[Money-framed time-donation] Rob pledged to donate $\$ 250$ worth of his time to Love Farm. This amounted to volunteering for 10 hours.

[Money-framed money-donation] Bill pledged to donate $\$ 250$ of his income to Love Farm.

[Time-framed money-donation] Bill pledged to donate 10 hours' worth of his income to Love Farm. This amounted to a cash donation of $\$ 250$.

Whose acts do you think was more praiseworthy?

Who do you think cares more about fighting hunger?

Who do you think has stronger moral character?

$$
\begin{aligned}
& -5 \text { (Rob) to } 5 \text { (Bill) } \\
& -5 \text { (Rob) to } 5 \text { (Bill) } \\
& -5 \text { (Rob) to } 5 \text { (Bill) }
\end{aligned}
$$

Hugh and Jack both work in Austin, TX and earn $\$ 30$ per hour. They both made contributions to a charity called Delta Fix, which helps children with chronic diseases.

[Time-framed time-donation] Hugh pledged to donate 10 hours of his time to volunteer with Delta Fix.

[Money-framed time-donation] Hugh pledged to donate $\$ 300$ worth of his time to Delta Fix. This amounted to volunteering for 10 hours.

[Money-framed money-donation] Jack pledged to donate $\$ 300$ of his income to Delta Fix.

[Time-framed money-donation] Jack pledged to donate 10 hours' worth of his income to Delta Fix. This amounted to a cash donation of $\$ 300$.

Whose acts do you think was more praiseworthy?

Who do you think cares more about helping children with chronic diseases?

-5 (Hugh) to 5 (Jack)

-5 (Hugh) to 5 (Jack)

Who do you think has stronger moral character?

-5 (Hugh) to 5 (Jack)

Natalie and Rose both work in Irvine, CA and earn $\$ 35$ per hour. They both made contributions to a charity called Infra Help, which helps victims of natural disasters.

[Time-framed time-donation] Natalie pledged to donate 10 hours of her time to volunteer with Infra Help.

[Money-framed time-donation] Natalie pledged to donate $\$ 350$ worth of her time to volunteer with Infra Help. This amounted to volunteering for 10 hours.

[Money-framed money-donation] Rose pledged to donate $\$ 350$ of her income to Infra Help.

[Time-framed money-donation] Rose pledged to donate 10 hours' worth of her income to Infra Help. This amounted to a cash donation of $\$ 350$.

Whose acts do you think was more praiseworthy?

Who do you think cares more about helping victims of natural disasters?

Who do you think has stronger moral character?
-5 (Natalie) to 5 (Rose)
-5 (Natalie) to 5 (Rose)
-5 (Natalie) to 5 (Rose) 
Attention Check. Please check all of the following that were mentioned on the previous pages: helping the homeless ( $\mathrm{T})$, helping to fight bunger $(\mathrm{T})$, helping children with chronic diseases $(\mathrm{T})$, helping victims of natural disasters $(\mathrm{T})$, helping endangered animals $(\mathrm{F})$, helping preserve the coastline $(\mathrm{F})$, helping to prevent climate change $(\mathrm{F})$, helping to transport disabled people $(\mathrm{F})$. [These options were presented in a random order.]

\section{Supplementary Studies}

\section{Study S1}

Procedure: Items were counterbalanced and randomized as in Study 1.

Instructions: In this study, you will read some brief stories about people's behavior, and answer some questions. We are interested in your opinion, and there are no right or wrong answers. Please click on the arrow to continue.

\section{$\underline{\text { Items and Measures }}$}

Megan and Kate both work in Columbus, $\mathrm{OH}$ and earn about $\$ 70,000$ per year.

Megan volunteered for one week with Build a Dream, a charity that transports people to Nepal to build houses for villagers.

Kate donated $\$ 1350$ to Care Builders, a charity that hires local carpenters to build houses for villagers in Nepal.

Which of these two acts do you think, was more morally praiseworthy? Megan's volunteering or Kate's donation

Hugh and Jack work in Austin, TX and both earn about $\$ 80,000$ per year.

Hugh volunteered for a week with Delta Fix, a charity that transports volunteers to look after patients at a hospital in Vietnam.

Jack donated $\$ 1540$ to Viet Docs, a charity which hires local villagers to look after patients at a hospital in Vietnam.

Which of these two acts do you think, was more morally praiseworthy? Hugh's volunteering or Jack's donation

Natalie and Rose both work in Irvine, $C A$ and earn about $\$ 40,000$ per year.

Natalie volunteered for a week in India with Infra Help, a charity which transports people to India to help rescue flood victims.

Rose donated $\$ 770$ to Flood Rescue, a charity which hires local fishermen to help rescue flood victims in India.

Which of these two acts do you think was more morally praiseworthy? Natalie's volunteering or Rose's donation

Rob and Bill both work in Tempe, $\mathrm{AZ}$ and earn about $\$ 50,000$ per year.

Rob volunteered for a week with Crop Harvester, a charity that transports volunteers to help farmers in Cambodia.

Bill donated $\$ 960$ to Love Farm, a charity that hires local laborers to help farmers in Cambodia.

Which of these two acts do you think was more morally praiseworthy? Rob's volunteering or Bill's donation

Attention Check. Please check all of the following that were mentioned on the previous pages: carpenter $(\mathrm{T})$, farmer $(\mathrm{T})$, hospital $(\mathrm{T})$, flood victims $(\mathrm{T})$, coffee $(\mathrm{F})$, concrete $(\mathrm{F})$, fire $(\mathrm{F})$, politician $(\mathrm{F})$. [These options were presented in a random order.]

\section{Study S2}

Procedure: Participants received either the time-donation, money-donation, or time-framed money-donation for each of these items (counterbalanced using a Latin square). Items were completed in a random order and dependent measures were presented on the same screen. 
Instructions: In this study, you will read three brief stories and answer some questions. We are interested in your opinion, and there are no right or wrong answers. Please click on the arrow to proceed.

\section{Items and Measures}

Megan works in Columbus, $\mathrm{OH}$ and earns about $\$ 70,000$ per year.

[Time-donation] Megan volunteered for a week with Build a Dream, a charity that transports people to Nepal to build houses for villagers.

[Money-donation] Megan donated $\$ 1350$ to Build a Dream, a charity that hires local carpenters to build houses for villagers in Nepal.

[Time-framed money-donation] Megan pledged to donate all of her earnings for one week to Build a Dream, a charity that hires local carpenters to build houses for villagers in Nepal.

How praiseworthy do you think Megan's act was? ${ }^{1} \quad 0$ (Not particularly praiseworthy) to 10 (Extremely praiseworthy)

How much do you think. Megan cares about people in Nepal? 20 (Not at all) to 10 (Very much)

How positive do you think Megan's moral character is? ${ }^{3} \quad 0$ (Not very positive) to 10 (Extremely positive)

Hugh works in Austin, TX and earns about $\$ 80,000$ per year.

[Time-donation] Hugh volunteered for a week with Delta Fix, a charity that transports people to Vietnam to look after patients at a hospital.

[Money-donation] Hugh donated $\$ 1540$ to Delta Fix, a charity that hires local villagers to look after patients at a hospital in Vietnam.

[Time-framed money-donation] Hugh pledged to donate all of his earnings for one week to Delta Fix, a charity that hires local villagers to look after patients at a hospital in Vietnam.

How praiseworthy do you think Hugh's act was? $\quad 0$ (Not particularly praiseworthy) to 10 (Extremely praiseworthy) How much do you think Hugh cares about people in Vietnam? 0 (Not at all) to 10 (Very much)

How positive do you think. Hugh's moral character is? $\quad 0$ (Not very positive) to 10 (Extremely positive)

Natalie works in Irvine, CA and earns about $\$ 40,000$ per year.

[Time-donation] Natalie volunteered for a week with Infra Help, a charity that transports people to India to help rescue flood victims.

[Money-donation] Natalie donated $\$ 770$ to Infra Help, a charity that hires local fishermen to help rescue flood victims in India.

[Time-framed money-donation] Natalie pledged to donate all of her earnings for one week to Infra Help, a charity that hires local fishermen to help rescue flood victims in India.

How praiseworthy do you think Natalie's act was? How much do you think Natalie cares about people in India? How positive do you think Natalie's moral character is?
0 (Not particularly praiseworthy) to 10 (Extremely praiseworthy)

0 (Not at all) to 10 (Very much)

0 (Not very positive) to 10 (Extremely positive)

Attention Check: Please check all of the following that were mentioned on the previous pages: carpenter (T), India (T), hospital $(\mathrm{T})$, flood victims $(\mathrm{T})$, coffee $(\mathrm{F})$, concrete $(\mathrm{F})$, fire $(\mathrm{F})$, politician $(\mathrm{F})$. [These options were presented in a random order.]

\footnotetext{
1 Participants were instructed: "On this scale, assume that 0 corresponds to an act that is completely morally neutral - like brushing one's teeth in the morning. Assume that 10 corresponds to an act of pure martyrdom - like sacrificing one's life for a stranger."

2 Participants were instructed: "On this scale, assume that 0 corresponds to not caring about them at all. Assume that 10 corresponds to caring about them as one would care about one's own children."

3 Participants were instructed: "On this scale, assume that 0 corresponds to someone who follows the law but who does not go out of hteir way to help others. Assume that 10 corresponds to the most saint-like person in the world."
} 